\title{
IMPULSO GUBERNAMENTAL Y ACCIÓN PARLAMENTARIA EN EL ÁMBITO DE LA REFORMA AGRARIA REPUBLICANO-SOCIALISTA DURANTE 1931*
}

por

MARIANO JUAN-RAMÓN DíAZ ÁLVAREZ

Dpto. $\mathrm{H}^{\mathrm{a}}$ Contemporánea. Instituto de Historia, CSIC.

RESUMEN: El compromiso de aplicar la reforma agraria gravitó especialmente sobre los diversos Gobiernos republicano-socialistas durante el primer año del Bienio Reformista (1931-1933), como un factor político primordial de la acción gubernamental, por lo que la aprobación de dicha reforma fue asumida inicialmente con carácter de urgencia en una coyuntura socio-económica marcada especialmente por un grave desempleo rural, jornalero en su mayor parte, en el mediodía español, y por la esperanza de un campesinado «bambriento de tierras» en la promesa inequivoca de redención efectuada por el Gobierno Provisional republicano nada más acceder al poder, el 14 de abril de 1931, y consistente, en sustancia, en la puesta en marcha de una reforma agraria fundamentada en una justa redistribución de la propiedad terrateniente. Sin embargo, los avatares de una coyuntura politica muy conflictiva y los intereses contrapuestos de los partidos integrantes de la coalición gubernamental dilataron la aprobación de los primeros proyectos de reforma agraria elaborados en 1931, por la Comisión Técnica Agraria, primero; el propio Gobierno, después; y dictaminados por la Comisión Parlamentaria Especial de las Cortes Constituyentes, finalmente.

Palabras Clave: España. Siglo XX. Segunda República. Reforma Agraria. Comisión Técnica. Comisión Ministerial. Comisión Parlamentaria.

SiglaS MÁS UTILIZADAS: CRA: Comisión Parlamentaria Especial de Reforma Agraria; CTA: Comisión Técnica Agraria; DSCC: Diario de sesiones de las Cortes Constituyentes (1931-1933); IRA: Instituto de Reforma Agraria; LBRA: Ley de Bases para la Reforma Agraria de 15 de septiembre de 1932; PLBRA: Proyecto de ley de Bases para la Reforma Agraria; RPCC: Reglamento provisional de las Cortes Constituyentes, de 18 de julio de 1931. 
ABSTRACT: During the first year of the Bienio Reformista (1931-1933), the republicansocialist governments of the Spanish Second Republic assumed that agrarian reform was not only an electoral promise but also an urgent solution for the desperate, bungry peasantry of Andalusia, a region with bigh unemployment, above all among the «jornaleros». After the Republic was proclaimed on 14 April, 1931, popular bopes of a rapid reform based on the redistribution of large estates was one of the most important aims of the Leftist parties within the government. However, the increasingly polarised political climate and contradictory interests within the governing coalition delayed the Agrarian Reform Act until 1932. The aim of this paper is to make a comparative analysis of the rules and regulations relating to agrarian reform made by the "Comisión Técnica", the "Comisión Ministerial" and the "Comisión Parlamentaria".

KEY WORDS: Spain. Twentieth century. Second Republic. Agrarian Reform.

\section{INTRODUCCIÓN}

Con la realización de este trabajo de investigación hemos pretendido, sobre todo, presentar una panorámica jurídico-positiva y comparada de los dos primeros proyectos de reforma agraria propugnados en España durante el primer año de la II ${ }^{2}$ República: el de la Comisión Técnica Agraria de julio de 1931, y el presentado en el Congreso de los Diputados por el Presidente de Gobierno, Alcalá-Zamora, en el siguiente mes de agosto. Así como un análisis de los dos Dictámenes de la Comisión Especial de Reforma Agraria de las Cortes Constituyentes sobre el proyecto gubernamental, de 7 de octubre y 26 de noviembre del mismo año. El estudio de todos los proyectos nos permite valorar la especial repercusión de estos precedentes normativos en la aprobación posterior del texto fundamental en la materia: la Ley de Bases de 15 de septiembre de 1932. Este trabajo investigador, de carácter esencialmente técnico-jurídico, se apoya sobre todo en el análisis de fuentes primarias y en una lectura selectiva de la bibliografía especializada sobre la reforma agraria republicana en España. Dentro de las primeras, se ha trabajado con los propios textos normativos de los distintos proyectos y dictámenes; el Reglamento Provisional de las Cortes Constituyentes, de 18 de julio de 1931; y, muy especialmente, el Diario de sesiones de las Cortes Constituyentes y las Actas de las reuniones celebradas por la Comisión Parlamentaria Especial de Reforma Agraria (rigurosamente inéditas y soporte básico de esta investigación). Junto a dichas fuentes primarias, se recogen algunos testimonios de los principales protagonistas coetáneos, tanto técnicos como políticos (Sánchez Román, Pascual Carrión, Vázquez Humasqué, Alcalá-Zamora, Azaña, Marcelino Domingo, Largo Caballero ...), y se presenta una síntesis valorativa en cada uno de los epígrafes específicos acerca de la evolución comparada de los proyectos y dictámenes de reforma agraria del Gobierno republicano-socialista durante 1931. 


\section{EL PROYECTO PARA LA SOLUCIÓN DEL PROBLEMA DE LOS LATIFUNDIOS DE LA COMISIÓN TÉCNICA AGRARIA}

Con la proclamación el 14 de abril de 1931 de la II $^{\mathrm{a}}$ República, tras la celebración de elecciones municipales en toda España dos días antes, y como consecuencia directa del plebiscito popular que representaron en favor del cambio de la forma de gobierno, se operaba una radical transformación del régimen político y de la clase dirigente en nuestro país. Como efecto inmediato de la nueva coyuntura política, el llamado Comité Revolucionario pasaba a ejercer el poder efectivo de la nación como Gobierno Provisional, con la aprobación de los correspondientes decretos nombrando a su presidente y a sus ministros ${ }^{1}$. Una de sus primeras acciones gubernamentales fue precisamente la aprobación mediante decreto de su primera declaración institucional, el Estatuto Jurídico, con fecha del mismo 14 de abril (Gaceta de Madrid, de 15 de abril) en la que afirmaba asumir «plenos poderes» de la voluntad nacional con «carácter de transitorio órgano supremo", en espera de la elección de Cortes Constituyentes, manifestando expresamente que sometería su actuación a derecho ${ }^{2}$. Tras hacer referencia, entre otras, a las libertades de creencia y cultos, y a la aspiración respecto a los derechos ciudadanos de «ensancharlos" y adoptar amplias garantías para su amparo, prescribía expresamente en el punto $5^{\circ}$ del decreto que:

«El Gobierno provisional declara que la propiedad privada quede garantida por la ley; en consecuencia, no podrá ser expropiada, sino por causa de utilidad pública y previa la indemnización correspondiente. Mas este Gobierno, sensible al abandono absoluto en que ha vivido la inmensa masa campesina española, al desinterés de que ha sido objeto la economía agraria del país, y a la incongruencia del derecho que la ordena con los principios que inspiran y deben inspirar las legislaciones actuales, adopta como norma de su actuación el reconocimiento de que el derecho agrario debe responder a la función social de la tierra»3.

La expresa voluntad de adecuar este derecho agrario a la función social de la propiedad terrateniente, llevó al Gobierno a impulsar toda una batería de decretos en materia económico-social que, por lo que se refiere al ámbito de la reforma agraria, implicaría una clara e inmediata apuesta en su favor. En efecto, con fecha 21 de mayo de 1931, serían aprobados sendos Decretos ${ }^{4}$ por los que se establecía la constitución y se nombraban los miembros de una Comi-

\footnotetext{
1 Gaceta de Madrid, Núm. 105, de 15 de abril de 1931.

2 «El sentido profundo de la revolución española fué éste: entrar España en la ley, vivir España plenamente, dignamente, la vida del derecho. Este afán fué el que unió y comprometió a las fuerzas heterogéneas que entraron en la revolución» (DomINGO, Marcelino: La experiencia del poder, Madrid, 1934, pp. 95-96).

3 Gaceta de Madrid, Núm. 105, de 15 de abril de 1931.

4 Gaceta de Madrid, Núm. 142, de 22 de mayo de 1931.
}

Hispania, LXIV/1, núm. 216 (2004) 267-324 
sión Técnica Agraria (CTA), con la finalidad concreta, entre otras, de «redactar las bases jurídico-económicas en que ha de inspirarse la reforma agraria» $\left(\right.$ art. $1^{\circ}$ ). Es interesante dedicar cierta atención a la Exposición de motivos del primero de los decretos, porque en ella hay ciertas referencias conceptuales muy ilustrativas acerca de la reforma, su finalidad y su contextualización. En primer lugar, se resaltaba, de nuevo, como presupuesto legitimador, la función social de la propiedad, en el sentido de que el derecho sobre el suelo que ella ampara, implica un «derecho funcional de fines transpersonales, o sea con el carácter de servicios públicos», que en el contexto de crisis política y económica surgido tras la Primera Guerra Mundial (1914-1918), va a impulsar diversos procesos de reforma agraria (a los que se alude), tanto en Europa Oriental como en Hispanoamérica, fundamentalmente en su condición redistributiva de la propiedad terrateniente. En consecuencia, el Gobierno Provisional:

«se decide a acometer en toda su vastedad la reforma agraria española seguro de que ahí radica el eje de la transformación social, política e industrial de España, porque ello ha de representar la modificación de las clases, la posibilidad de una democracia aldeana y la creación de una capacidad adquisitiva en los campesinos que inevitablemente ha de repercutir en la industria».

Para ello, se crea un organismo asesor ad boc, la CTA, responsable de elaborar los proyectos de reforma agraria y sus planes de ejecución junto con las instituciones complementarias competentes, con facultades suficientes para recabar, según el artículo $4^{\circ}$, la colaboración de los organismos del Estado que requiriese (Consejo de Economía Nacional, Oficina del Catastro, Consejo de Agricultura, etc.). Dicha CTA la integraban, según el Decreto de nombramiento de igual fecha, 21 de mayo de 1931, un total de 33 miembros: el Presidente, Felipe Sánchez Román; y los vocales siguientes: el Director General de los Registros y del Notariado - en el decreto no se menciona a su titular, pero Pascual Carrión nos informa que era Antonio Garrigues-5; los ingenieros agrónomos, Adolfo Vázquez Humasqué, Manuel Alvarez Ugena, Pascual Carrión, Eduardo Rodrigáñez, José Oteyza, y Enrique Alcaraz; los ingenieros de montes, Eladio Romero, y Antonio Lleó; el Director de la Misión biológica de Galicia, Cruz A: Gallástegui; los profesores, Juan Dantín, Juan Morán, y Luis de Hoyos; los economistas, Antonio Flores de Lemus, Agustín Viñuales y Gabriel Franco; los juristas y expertos, Carlos López de Haro, Blas Infante; José de Eguizábal, Filiberto Villalobos, Constancio Bernaldo de Quirós, Carlos Jordá, Luis Casuso y Mariano Granados; los agricultores, Juan Miguel Sugrañes, José Tudela, Manuel Alba, y Juan Díaz del Moral; los obreros, Lucio Martínez Gil y Francisco Zafra, y los administrativos, Mariano Fuentes y Antonio Here$\mathrm{za}^{6}$. En definitiva, un verdadero elenco de algunos de los especialistas más bri-

\footnotetext{
5 CARrión, Pascual: Los latifundios en España, Barcelona, 1975, $2^{\mathrm{a}}$ ed., p. 352.

6 Gaceta de Madrid, Núm. 142, de 22 de mayo de 1931.
} 
llantes en la materia que, así mismo, destacarían posteriormente en la tramitación parlamentaria en las Cortes (tanto dentro de la CRA, como en el Pleno de la Cámara) del PLBRA de Marcelino Domingo de marzo de 1932. Abundando en esta línea, su presidente, Sánchez Román, catedrático de Derecho Civil y diputado liberal por la Agrupación al Servicio de la República en la legislatura constituyente, matizaría en el debate de totalidad de dicho proyecto que en la CTA «se reunieron al servicio de la causa pública gentes de una condición verdaderamente ilustre en cada uno de los ramos del saber de su especialidad (...) Yo no he encontrado jamás en mi vida de intervención oficial mejores gentes reunidas, ni con más entusiasmo, ni con más preparación para emprender aquel trabajo» 7 .

La Comisión, para el mejor desempeño de sus funciones, estaba capacitada para dividirse en diversas Subcomisiones (artículo $3^{\circ}$ ); y así lo hizo, en efecto, con la creación de las de arrendamientos y aparcerías; de rescate y ordenación de bienes comunales; de crédito agrícola, de redención de cargas (foros, rabassa morta...) etc.; destacando en particular, la que se formó para "proponer las medidas dedicadas a acometer el problema de los latifundios», integrada por el propio presidente, Sánchez Román; los economistas, Flores de Lemus y Viñuales; y los ingenieros agrónomos, Pascual Carrión y Eduardo Rodrigáñez. Por cierto que, para el secretario del Congreso de los Diputados durante la legislatura constituyente, el socialista Juan-Simeón Vidarte, Felipe Sánchez Román, de ideas «sólidamente republicanas», era, sin embargo, en el aspecto social "una de las figuras más reaccionarias de la República» ${ }^{8}$. Opinión de la que discrepamos por completo, ya que fue, precisamente, este diputado liberal uno de los defensores más ardientes de la aplicación del criterio de unidad-propietario (cómputo de toda la superficie acumulada de tierras susceptibles de expropiación por cada uno de sus dueños, tomando como base todo el territorio de la República, a los efectos de aplicar, por una parte, los topes máximos de tierra disponible para ellos; y, por la otra, para delimitar las tierras expropiables por exceder de esa superficie máxima no afectada), frente al criterio de unidad-finca (cómputo de dichas tierras de forma unitaria, sin acumulación ninguna). Controversia ésta de enorme trascendencia política y técnico-jurídica en los avatares de la tramitación parlamentaria del PLBRA de Marcelino Domingo, por el contundente ataque que suponía el criterio apoyado por Sánchez Román para

7 DSCC, núm. 175, de 1 de junio de 1932, p. 5.950. Se llama la atención, especialmente, sobre ésta y las restantes citas de Sánchez Román relativas a su intervención en la discusión plenaria de totalidad del PLBRA de Domingo (mayo-septiembre de 1932), porque aportan apreciaciones de gran interés sobre las circunstancias de elaboración de la ponencia de la CTA, que, hasta ahora, no habían sido destacadas como merecen por la historiografía especializada, porque una fuente primaria tan fundamental como es el DSSC en lo que se refiere a dicha discusión parlamentaria no ha sido estudiada a fondo en su integridad.

${ }^{8}$ La información sobre la constitución y los integrantes de dicha Subcomisión, en CARRIóN, Pascual: Op. cit., p. 352. La cita del secretario del Congreso de los Diputados, en VIDARTE, JuanSimeón: Las Cortes Constituyentes de 1931-1933, Barcelona, 1976, p. 471.

Hispania, LXIV/1, núm. 216 (2004) 267-324 
los grandes propietarios terratenientes del país en general, sin que se tuviera en cuenta ninguna otra circunstancia subjetiva (titulación nobiliaria, por ejemplo) en las condiciones de titularidad del dominio, además de la de ser propietario.

El proyecto de la Subcomisión de latifundios de la CTA fue elaborado durante los meses de junio y julio de $1931^{9}$, aprobado en el pleno de dicha comisión, y presentado finalmente por los ponentes Sánchez Román, Flores de Lemus y el propio Pascual Carrión, al primer Gobierno republicano-socialista -el mismo Gobierno Provisional, pero ya ratificado, por aclamación, por las Cortes Constituyentes-, en la sesión del Consejo de Ministros del 23 de julio, una vez celebradas las elecciones generales en el mes de junio anterior. El proyecto constaba de 18 bases algunas de las cuales pasamos a considerar con cierto detenimiento porque, como veremos, en él se establecían principios y fundamentos en materia de reforma agraria (institucionales, organizativos, de ejecución), que tendrían enorme influencia en los sucesivos proyectos que se irían presentando de acuerdo con los cambios de la coyuntura política.

En la Base $1^{\text {a }}$ se hacía expresa referencia a su aprobación mediante Decreto gubernamental - sin intervención de las Cortes, por tanto- y a su entrada en vigor al día siguiente de la publicación en la Gaceta de Madrid. En este sentido, Manuel Azaña se refirió en su diario a que el propio Sánchez Román le había explicado las líneas generales del mismo, pareciéndole bien y estando de acuerdo, además, «en que habrá que promulgarlo por decreto, porque la urgencia es grandísima». El presidente de la CTA; a su vez, ratificó, posteriormente, dicha opinión de Azaña, cuando declaró en el mencionado debate plenario en las Cortes Constituyentes que:

«Aquel dictamen, que respondía a un problema de urgencia [el del paro campesino], que ideaba unas instituciones posesorias para acometerlo, murió en el ánimo del Gobierno, con la sola excepción pública, ya que de otra manifestación de este carácter yo no tengo noticia: me refiero al entonces Ministro de la Guerra, actual Presidente del Consejo de Ministros, que dijo en algún acto político que aquella reforma él era partidario de implantarla por decreto en vista de todas estas circunstancias que os estoy recordando» 10 .

Dicha Base $1^{\text {a }}$, igualmente, establecía el principio de retroactividad normativa sobre «las situaciones jurídicas particulares que con relación a la propiedad rústica se hubieran creado voluntariamente», desde la fecha de proclamación de la II ${ }^{\mathrm{a}}$ República, hasta la promulgación del decreto; prescribiéndose que «se

9 El proyecto íntegro está publicado como apéndice en CARrón, Pascual: Op. cit., pp. 383393, y también en Federación Nacional de Trabajadores de La Tierra [FNTT]: Memoria del II congreso 1932., Jaén, 2000, $1^{\text {a }}$ ed. facsímil, pp. 337-346.

${ }^{10}$ Las citas de los entonces Ministro de la Guerra y Presidente de la CTA, respectivamente, en AZAN̄A, Manuel: Memorias políticas y de guerra. Diario-Discursos 1931, vol. I, Madrid, 1976, p. 43, Anotación de 8 de julio de 1931, y en DSCC, núm. 175, de 1 de junio de 1932, p. 5.950. 
tendrán por no constituidas (...) en cuanto se opusieren a la aplicación» del mismo ${ }^{11}$. Además, se recogía el compromiso de asentar entre 60.000 y 75.000 familias campesinas durante el primer año, más un cupo de asentamientos para los siguientes años determinable por el Gobierno, así mismo por decreto. El reparto de dicho cupo anual entre las provincias afectadas suponía, según Pascual Carrión, la entrega de tierras a unas 4.000-5.000 familias por provincia, 0 , dicho en otros términos, 100-200 familias por pueblo entre los 30-40 municipios en los que las tierras serían distribuidas, preguntándose al respecto el ingeniero agrónomo: «¿Es posible que la reforma agraria tenga alguna eficacia con menos amplitud?», sobre todo, cuando se preveía un período de diez a doce años para la aplicación plena y eficaz de la reforma ${ }^{12}$. Esta base primera inspiró, casi en su misma literalidad, todos los proyectos posteriores incluyendo a la propia LBRA de septiembre de 1932. Así, el mencionado principio de retroactividad normativa va a ser aplicado en todos ellos con el fin de condicionar la validez jurídica de todas las transmisiones contractuales de la propiedad de la tierra, para evitar la defraudación de la normativa especial de reforma agraria, y su consecuencia directa: la menor disponibilidad de fincas rústicas para redistribuir entre los campesinos beneficiarios.

En la Base $2^{\text {a }}$ se determinaban los términos municipales de las provincias en las que iba a implantarse, en primer lugar, el programa de asentamientos mediante ocupación temporal, que eran las de Andalucía, las de Extremadura, Ciudad Real y Toledo; y la única causa legitimadora: la gravedad del paro campesino allí existente. Para el ilustre presidente de la CTA:

\footnotetext{
11 Entre las varias enmiendas que los vocales socialistas presentaron en el pleno de la CTA a esta ponencia sobre la solución al problema de los latifundios, una de las que fueron admitidas, precisamente, fue la relativa a la retroactividad, siendo rechazadas la mayor parte, por lo que presentarían un voto particular que sería remitido al Gobierno, firmado con fecha 8 de agosto de 1931 por los vocales obreros Martínez Gil y Francisco Zafra, y los representantes de los peritos agrícolas, los también socialistas Esteban Martínez Hervás y José $\mathbf{M}^{2}$ Soler. Dicho voto particular, con el que manifestaban expresamente su rechazo a la ponencia de la CTA, implicaba, entre otros aspectos: una implícita oposición al régimen de ocupación temporal (justificado por la escasez de recursos económicos del Estado, según los economistas de la Comisión) y un rotundo apoyo a las expropiaciones, límites de superficie más restringidos para los dueños de las fincas expropiables, la inclusión adicional de las provincias de Albacete y Salamanca, la nacionalización de la propiedad expropiada, la demanda de un impuesto sobre la renta de todos los españoles, o la elevación a 150.000 del número de familias asentadas como cupo máximo para el primer año, frente al de 75.000 de la ponencia. El voto particular, no obstante, sería posteriormente retirado por Martínez Gil, a la hora de discutir en el seno de la Comisión parlamentaria de Reforma Agraria (CRA) el siguiente proyecto, ya gubernamental, presentado por Alcalá-Zamora en agosto, para no dilatar más su aprobación, «en consideración a la urgencia que existe en emitir cuanto antes el dictamen y por la oposición que encuentra la reforma» (Archivo Cortes, Congreso de los Diputados, Serie General, Legajo 543, Exp. 1, Acta de la sesión de la CRA, de 10 de septiembre de 1931). Tanto la información sobre la aceptación de la enmienda sobre la retroactividad, como el contenido íntegro del voto particular en FNTT: Memoria.... Op. cit., pp. 337 y 346-348

12 Carrón, Pascual: Op. cit., pp. 353 y 359.
} 
«Ese organismo vivía entonces bajo la presión terriblemente angustiosa del paro campesino andaluz y extremeño. Se creyó en el deber, previa consulta al Gobierno y en parte siguiendo inspiraciones de él o de alguno de sus miembros y representantes, de tomar esencial preocupación de aquel problema, para ver si podía atacarlo antes de que su desarrollo pudiera tener las consecuencias que el ímpetu revolucionario que allí se suponía existente, pudiera ocasionar, y se propuso la Comisión agraria anticiparse a todo movimiento espontáneo de aquellos obreros andaluces campesinos, para dar cauce legal a un fenómeno que nosotros teníamos la convicción de que se iba a producir; pues era previsible, en efecto, que alguna incontinencia popular se tradujera necesariamente en la ocupación directa de las tierras» 13 .

También confirmó la gravedad del paro campesino testimoniada por Sánchez Román en las Cortes Constituyentes, Adolfo Vázquez Humasqué (el mayor especialista agrario de Acción Republicana [AR], nombrado vocal de la CTA como ingeniero agrónomo y, posteriormente, primer Director General de Reforma Agraria), para quien:

«Es innegable que el problema de Andalucía y Extremadura, principalmente, no puede remediarse simplemente, como pretenden la mayoría de los propietarios, con mejoras de jornales, seguros contra el paro, arriendos moderados y aparcerías generosas. Hay que atacar la entraña del régimen de la propiedad, al mismo tiempo que se inicien metódica y regularmente los estudios técnicos para ir a una transformación cultural, científica y progresiva» ${ }^{14}$.

No obstante, se contemplaba una posible aplicación futura de los asentamientos en los términos municipales de otras provincias, si así lo aprobaba el Consejo de Ministros — sin intervención parlamentaria, por tanto- ${ }^{15}$, con el

${ }_{13}$ DSCC, núm. 175, de 1 de junio de 1932, p. 5.950.

14 VÁZQUEZ HUMASQUÉ, Adolfo: Del momento actual sobre el agro español: Mi proyecto de reforma agraria, Madrid, 1931, p. 21.

is Sin embargo, en la LBRA de 15 de septiembre de 1932, sí se exigiría la intervención preceptiva de las Cortes, al ordenarse que la extensión de la reforma agraria a otras provincias sólo podría llevarse a cabo mediante ley, y no mediante decreto gubernamental. Esta evidente restricción a la capacidad de maniobra gubernamental en beneficio de un más efectivo control parlamentario, se aprobaría por iniciativa del propio Presidente del Coñsejo de Ministros, Manuel Azaña, que conseguiría modificar, en un sentido de mayor moderación, algunos de los aspectos más radicales de los dictámenes del PLBRA de la CRA de 7 de octubre y 26 de noviembre de 1931, confirmando un mayor protagonismo por su parte en el ámbito de la reforma agraria del que se le ha venido reconociendo por la historiografía especializada (así, por ejemplo, en los cambios introducidos en el PLBRA de marzo de 1932 y, sobre todo, en su directa intervención en la cuestión ya apuntada de la discusión sobre el criterio de la unidad-finca -del que era partidario Azaña- frente al criterio de la unidadpropietario; controversia que generó cierta dilación en la tramitación parlamentaria de dicho proyecto dictaminado, por las divergencias políticas producidas, al respecto, entre los partidos de la mayoría gubernamental, tanto en el seno de la CRA, como en el propio Salón de Sesiones de las

Hispania, LXIV/1, núm. 216 (2004) 267-324 
informe previo del organismo técnico competente que, según el proyecto, era el IRA. Este instituto, regulado en la Base $3^{\mathrm{a}}$, debía constituirse como corporación de interés público, con el objetivo primordial de «transformar la constitución agraria española». Para ello se le dotaba de personalidad y responsabilidad jurídicas en el desempeño de sus funciones, con autonomía económica y un capital inicial de diez millones, posteriormente incrementado con las reservas por él mismo acumuladas y, en concreto, por la percepción íntegra del gravamen tributario establecido por el propio decreto en su base sexta, y que afectaba a toda la propiedad rústica en todo el territorio nacional.

Así mismo, propugnaba dicho decreto la puesta en marcha de otros organismos públicos, con «carácter preparatorio», en tanto el entramado estructural del IRA se consolidara y operase eficazmente. Así, en la Base $4^{\mathrm{a}}$, adquirían carta de naturaleza tanto la Junta Central Agraria como las diversas Juntas Locales Agrarias. A estas Juntas se encomendaba la promoción de la constitución de comunidades campesinas, sus asambleas, asociaciones y sindicatos, cooperativas, etc., procurando implantar efectivamente la reforma hasta que el IRA funcionase con normalidad. No obstante, el proyecto prescribía en su base $8^{a}$, que sería competencia de la Junta Central Agraria, decretar la ocupación de las tierras propuestas para tal fin por las Juntas Locales.

En cuanto a las tierras afectadas por la reforma, el proyecto especificaba la clase y tipología de las mismas de acuerdo con las «limitaciones» que la Base $5^{\text {a }}$ imponía sobre la propiedad rústica en todo «el territorio nacional de la República», en función de un doble criterio restrictivo: por un lado, no superar el tope máximo establecido de superficie disponible para sus propietarios, según el tipo de tierras cultivables ${ }^{16}$, y por el otro, no disfrutar de una renta catastral superior a 10.000 pesetas o, en su defecto — por no estar todavía implantado el Catastro en la provincia correspondiente- de la renta equivalente del líquido imponible. Hay que tener en cuenta al respecto, que la superficie total catastrada era de unos 25 millones de hectáreas en números redondos, aproximadamente el $50 \%$ del total nacional. En este sentido, el ingeniero agrónomo Gabriel García-Badell, destacado conocedor de la materia, declararía que; gracias a los datos obtenidos en su mayor parte por el Servicio de Catastro, en las áreas donde se proyectaba aplicar la reforma agraria, se contaba con un avance

Cortes. Y todo ello, dato de relevancia a retener, antes de que se produjera el golpe de Estado del general Sanjurjo).

16 «En el plan de rapidez que proyectaba la Reforma, la superficie es elemento más fácil de determinar que el valor y no admite las discusiones que éste. Si para valorar las fincas tomamos los datos catastrales, no serían comparables las provincias que se hicieron antes y después de la guerra mundial, y si han de adoptarse coeficientes de corrección y realizar revisiones sería preciso mucho tiempo». (CARrión, Pascual: Op. cit., p. 365). En este sentido, Le Coz ha destacado cómo «la fijación de superficies tope para la propiedad es el instrumento empleado más frecuentemente en las políticas reformistas», ya que, en su opinión, «es el arma antilatifundista por excelencia» (LE COZ, Jean: Las Reformas Agrarias, Barcelona, 1974, p. 279).

Hispania, LXIV/1, núm. 216 (2004) 267-324 
catastral que «ha podido ofrecernos una estadística con imperfecciones, pero muy aproximada a la realidad", teniendo en cuenta su finalidad esencialmente fiscal. No obstante, precisaba: "Quedan en España 24 millones de hectáreas por catastrar, que se rigen por los antiguos amillaramientos de 1860 y que se reparten un cupo fijo anual. De esta parte de España, casi su mitad, no tenemos datos ni siquiera aproximados sobre la distribución de la propiedad agrícola ni pueden obtenerse más que con la terminación del catastro» ${ }^{17}$.

Las tierras que quedaban afectadas eran las siguientes:

$1^{\circ}$ Las tierras de secano que excedieran de: 300 hectáreas dedicadas al cultivo herbáceo de alternativa; 200 hectáreas para cultivo arbóreo, olivo en especial, asociado o no a otros cultivos; 100 hectáreas destinadas al cultivo de la vid; y 400 hectáreas en dehesas de pasto y labor, o de pasto en exclusiva, arboladas o no. Para los vocales socialistas de la CTA, estos topes de superficie en tierras de secano de libre disposición para sus dueños eran demasiado elevados, por lo que los rebajaron en el mencionado voto particular que enviaron al Gobierno a 200 ha en los cultivos herbáceos de alternativa, a 100 ha en los arbóreos (igual tope que en los arbustivos), y a 300 ha en las dehesas referidas (de pasto, de pasto y labor, arboladas o no $)^{18}$.

$2^{\circ}$ Las tierras de regadío que excedieran de: 10 hectáreas en aquellos terrenos «comprendidos en las grandes zonas regables merced a obras realizadas con el auxilio del Estado y no comprendidas dentro de la ley de 7 de julio de $1905 »^{19}$.

$3^{\circ}$ Todas las tierras cuya renta catastral fuese superior a 10.000 pesetas. Con la expresa salvedad, de que allí donde no existiese valoración catastral, se computaría como renta el equivalente del líquido imponible. Esta limitación por razón de renta, no se establecía a los efectos de una posible ocupación temporal de la tierra generadora de dicha renta, sino para el cómputo del exceso gravado por el impuesto especial establecido en la base sexta, que afectaba a la riqueza rústica en todo el territorio nacional, con el fin de que todos los propietarios terratenientes, independientemente de que sus tierras fueran ocupadas o

17 GARCíA-BADELL, Gabriel: «La Reforma agraria y el Catastro» en Revista de los Servicios Socialagrarios y de Estadística Agrícola-social (Madrid) 3 (1932), p. 193.

18 FNTT: Memoria... Op. cit., p. 347. Por el contrario, en un documento de la Sociedad de Labradores de Jaén en el que se recogían diversos comentarios al "proyecto de reforma agraria, 1931» se planteaban baremos muy distintos, afirmando taxativamente sobre dicha afectación que: «La fijación de superficies a cada cultivo será siempre una lamentable equivocación, (...) El tipo de 300 hectáreas para las tierras calmas resulta muy bajo y el de 400 para los pastos (...) terminaría por arruinar la ganadería nacional que ya arrastra una vida lánguida» (Archivo Cortes, Congreso de los Diputados, Serie General, Legajo 544, Exp. 1, doc. N 63 ).

19 Este supuesto concreto de las tierras de regadío afectadas para la ocupación temporal, era absolutamente idéntico al propuesto por los socialistas en su voto particular enviado al Gobierno, posteriormente, con fecha 8 de agosto de 1931 (FNTT: Memoria... Op. cit., p. 347).

Hispania, LXIV/1, núm. 216 (2004) 267-324 
no, contribuyeran a financiar las medidas de reforma agraria propugnadas por la CTA. En este sentido, el profesor Juan Pro, que ha investigado en profundidad la evolución del Catastro en España, ha destacado cómo la idea de este impuesto progresivo sobre las rentas de la propiedad rústica, la tomó la CTA del proyecto de reforma fiscal de Santiago Alba, y cómo, aunque no hubiese sido rechazada la ponencia para la reforma agraria de dicha comision, «habría sido muy difícil de aplicar mientras el catastro no alcanzara todos los rincones del país y mientras conservara su estructura meramente local» 20 .

A los efectos del cálculo de los excesos de superficie, cuando se acumulaba más de una propiedad rústica en uno o más términos municipales de una misma provincia o en los de varias, la CTA adoptaba el criterio fundamental de la unidad-propietario frente al de la unidad-propiedad, con importantísimas consecuencias de cara a una mayor disponibilidad de tierras y, por tanto, para la mayor eficacia de la reforma en el asentamiento de las familias campesinas ${ }^{21}$.

La tierras propiamente afectadas eran objeto, en principio, de ocupación temporal (y no de expropiación) por causa de utilidad social, con la contrapartida para el propietario del derecho a percibir un canon fijado por el IRA. Sobre el alcance de una posible expropiación futura, el decreto se remitía, en su base $7^{\mathrm{a}}$, a una posterior ley de reforma agraria (o a otras especiales), que podría aplicarla en la medida en que las ocupaciones temporales - cuyo plazo sería señalado por esta ley - pasaran a ser definitivas. Con la aplicación del proyecto, por consiguiente, no era precisa la adquisición de las tierras, sus dueños mantenían la condición de propietarios, pasando a ser de hecho arrendadores de los asentados, verdaderos colonos, y el coste económico de la reforma, por tanto,

20 PRO, Juan: Estado, geometría y propiedad. Los orígenes del catastro en España (1715-1941), Madrid, 1992, pp. 313-314. Las valoraciones catastrales a efectos indemnizatorios para las tierras expropiables (renta catastral, amillarada, líquido imponible) suscitaría una de las mayores controversias habidas en las Constituyentes, tanto en el debate de totalidad, como en el de la base $8^{a}$ del Dictamen del PLBRA que las regulaba.

${ }^{21}$ Uno de los cambios más moderados y restrictivos para la afectación de tierras de la LBRA de 1932, comparando con la ponencia de la CTA y con los dictámenes de la CRA del PLBRA presentado por Alcalá-Zamora en agosto de 1931, fue precisamente el de la adopción del criterio de la unidad-propietario desde una base territorial de cómputo municipal y no nacional, aunque teniendo en cuenta, por un lado, que en el dictamen inicial de abril de 1932 el criterio contemplado era exclusivamente el de la unidad-finca; y, por el otro, el conflicto político (del que ya se ha hecho un breve apunte) que generaría dentro de la mayoría parlamentaria gubernamental entre los socialistas (favorables al criterio de la unidad-propietario) y los republicanos de izquierda (contrarios al mismo), hay que considerar más bien la adopción final de dicho criterio, aun con la restricción territorial matizada, como una concesión política de los sectores republicanos de izquierda de la coalición gubernamental a sus compañeros de la minoría socialista para evitar una seria crisis del poder ejecutivo, frente a la tesis tradicional de historiadores como Malefakis y Maurice, que han sostenido que la concesión se hizo a los sectores de la burguesía agraria, sin mayor matiz sobre la evolución comparada de dicho criterio entre proyecto y dictamen, ni referencia alguna sobre la fuerte controversia política suscitada entre las minorías gubernamentales tanto en la CRA como en el salón de sesiones de las Cortes. 
según Pascual Carrión, «quedaba muy disminuido». Malefakis, por su parte, ha sostenido que con las ocupaciones temporales revivían los arrendamientos obligatorios propuestos por los reformadores ilustrados de finales del siglo XVIII. Finalmente, para Jacques Maurice, con el asentamiento de campesinos como colonos «casi permanentes», se plasmaba en el proyecto la influencia del reformismo agrario burgués, de acuerdo con las tesis de Joaquín Costa (colectivismo agrario), por un lado, y de Henry George (intervencionismo del Estado mediante la política fiscal), por el otro ${ }^{22}$.

Igualmente, el proyecto incorporaba un impuesto especial - considerado como una de las fuentes de ingresos para el IRA, como ya se ha dicho, de carácter permanente - sobre la renta catastral de bienes rústicos, cuando ésta excediera de la cantidad de 10.000 pesetas, de acuerdo con una escala progresiva de tipos de gravamen establecida por la base $6^{a}$ (véase infra Cuadro 1). Con este impuesto especial, para Malefakis, se forzaba a los grandes propietarios terratenientes «a ayudar a pagar su propia liquidación», pero olvida este historiador que dicho gravamen se aplicaba a todos los propietarios de la tierra en toda España, y no sólo a los de las provincias latifundistas en los que se iban a aplicar los asentamientos. En este sentido, Jacques Maurice, con mayor acierto, ha interpretado la voluntad de los ponentes de «restringir el ámbito de la imposición a la renta rústica», como un intento por aislar políticamente a los grandes propietarios terratenientes de sus «aliados naturales», los oligarcas financieros. No obstante, y como ha puesto de manifiesto Jordi Palafox, hay que tener en cuenta que un impuesto sobre la renta de esta naturaleza «se oponía de manera frontal a los deseos del Gobierno cuyo objetivo económico fundamental en esta etapa fue tratar de equilibrar el presupuesto» ${ }^{23}$. Y en efecto, en el PLBRA definitivo presentado por el gobierno republicano-socialista de Azaña, en marzo de 1932, dicho impuesto especial quedaría suprimido finalmente, para satisfacción del propio Presidente de Gobierno, responsable máximo de su eliminación, siguiendo el criterio en este sentido de su Ministro de Hacienda, Jaime Carner ${ }^{24}$.

${ }^{22}$ Las opiniones expresadas por el ilustre ingeniero agrónomo y por los dos historiadores, en CARRIÓN, Pascual: Op. cit., p. 368, MALEFAKIS, Edward: Reforma agraria y revolución campesina en la España del siglo XX, Barcelona, 1980, $4^{2}$ ed., p. 208, y MAURICE, Jacques: La reforma agraria en España en el siglo XX (1900-1936), Madrid, 1978, $2^{\text {a }}$ ed., pp. 30-31, respectivamente.

${ }^{23}$ Las citas de los tres historiadores, en MalefaKis, E.: Op. cit., p. 209, MaURICE, J.: Op. cit., p. 31, y Palafox, J.: Atraso económico y democracia. La Segunda República y la economía española, 18921936, Barcelona, 1991, pp. 214-215, respectivamente.

${ }^{24}$ Sobre el criterio preferente de la política presupuestaria de Azaña, éste anotaría en su diario al hilo de sus conversaciones para formar el primer Gobierno constitucional, en diciembre de 1931, que: «Llamo a Carner (...) le digo que voy a nombrarle ministro de Hacienda. (...) Me pone otros inconvenientes: su criterio rígido en materia de presupuestos, que han de nivelarse a toda costa. Cuando me expone sus puntos de vista sobre el particular, me convenzo que he encontrado al hombre que necesitaba, capaz de llevar a cabo con verdadera energía lo que yo estimo indispensable 


\section{CUADRO 1}

GRAVAMEN ESPECIAL SOBRE LOS EXCESOS

DE RENTA CATASTRAL DE BIENES RÚSTICOS

\begin{tabular}{|c|c|c|c|}
\hline \multicolumn{3}{|c|}{ EXCESOS DE RENTA CATASTRAL EN PESETAS } & TIPO DE GRAVAMEN SOBRE EL EXCESO \\
\hline $\mathrm{de}$ & 10.001 & 20.000 & $10 \%$ \\
\hline & 20.001 & “ 30.000 & $20 \%$ \\
\hline & 30.001 & “ 40.000 & $30 \%$ \\
\hline “ & 40.001 & “ 50.000 & $40 \%$ \\
\hline & 50.001 & “ 100.000 & $50 \%$ \\
\hline “ & \multicolumn{2}{|c|}{100.001 en adelante } & $60 \%$ \\
\hline
\end{tabular}

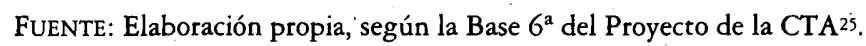

Respecto al orden de prelación para proceder a las ocupaciones temporales, la Base $11^{\mathrm{a}}$ establecía una serie de reglas por las que eran objeto preferente las «tierras de buena calidad más próximas a los núcleos urbanos, poblados o caseríos y vías de comunicación", y dentro de éstas: $1^{\circ}$ las incultas susceptibles de cultivo inmediato y rentable; $2^{\circ}$ las de cultivo deficiente; $3^{\circ}$ las de explotación indirecta; y $4^{\circ}$ las de buena explotación directamente gestionadas por sus propietarios. Finalmente, se recomendaba que la ocupación de las tierras guardara la debida proporción respecto a cada uno de los propietarios afectados.

En este apartado de la prelación de las tierras a ocupar, el proyecto de la CTA evidenciaba cuál era el objetivo principal de los asentamientos: poner tierras a disposición de los campesinos beneficiarios en donde pudiera emplearse más mano de obra desempleada, y obtener, de forma simultánea, el mayor volumen posible de producción agraria, es decir, asentamientos en los que el cultivo fuera intensivo en trabajo a la par que rentable económicamente. Por ello, el proyecto afectaba, preferentemente, las tierras del propietario cultivador directo de la tierra cuando se interpretaba que había una ineficiente explotación económica, bien por ausencia de un cultivo más rentable, bien por defi-

hacer (...). Resuelvo interiormente no soltar a Carner» (AZAÑA, M.: Op. cit., p. 568, Anotación de 14 de diciembre de 1931).

25 Para los tramos de exceso de renta catastral los socialistas propusieron unos tipos más elevados, y para el umbral concreto de más de 100.000 pesetas, un $70 \%$, que ascendía hasta el $80 \%$ si la renta superaba las 125.000 pesetas, con el importante matiz - no incluido en el texto de la ponencia de la CTA (más moderado también en este aspecto), pero sí en el voto particular a la totalidad remitido al Gobierno por la representación obrera-, de que se aplicarían estos tipos progresivos no sobre los tramos específicos de exceso de renta catastral, sino a partir de las 10.000 pesetas iniciales adoptadas como umbral de renta para el cómputo de dicho excesos (FNTT: Memoria... Op. cit., p. 348). 
ciencia en el cultivo objeto de explotación, en beneficio del propietario absentista que las había cedido, que quedaba afectado inmediatamente después. No obstante, si las tierras disponibles para la ocupación eran insuficientes, quedaban sujetas también - si bien en último lugar - las fincas rústicas del propietario cultivador directo, aunque los resultados de la explotación de la tierra fueran rentables. Ahora bien, tanto en este proyecto como en los posteriores y en la propia LBRA de 1932, el cultivador directo titular de una explotación modelo por su eficiencia técnicoeconómica va a quedar siempre exceptuado de la expropiación o de la ocupación temporal, en su caso; y en el de Alcalá-Zamora de agosto de 1931, como veremos, incluso el cultivador «a buen uso y costumbre», que ahora, por el contrario, cabe interpretar que sí quedaba incluido. En este sentido, hay que enfatizar que tanto los sectores republicanos más moderados como los de izquierda en el gobierno, trataron siempre en todos los proyectos dictaminados de obtener el mayor volumen de tierras disponibles para sus dueños en cultivo directo, frente a la postura de los socialistas que, de acuerdo con su preferencia por la explotación colectiva, sobre todo en tierras de secano, intentaron restringir todo lo posible en las negociaciones mantenidas con los grupos republicanos dicho volumen de tierras. Los socialistas, igualmente, lucharon con denuedo por mantener, dentro del dictamen definitivo del PLBRA de 1932, como tierras expropiables, aunque fueran explotadas directamente por sus propietarios, aquéllas con las que éstos pudieran ejercer un dominio político, social y económico en el término municipal, o dicho en otros términos, la causa expropiatoria por motivo de presión social. Lo cual conseguirían, en efecto, aunque la superficie de las fincas no excediera de los topes establecidos sin afectar, es decir, a libre disposición de sus propietarios.

En función del número de los asentamientos y del cupo de asentados, se creaban en cada término municipal una o más Comunidades de campesinos, con la finalidad de entrar en la posesión y explotación de las tierras seleccionadas (bases $11^{\mathrm{a}}$ y $12^{\mathrm{a}}$ ), una vez levantada la correspondiente acta de ocupación en presencia de la Junta Local y del propietario de las mismas (base $13^{\mathrm{a}}$ ). Estas comunidades campesinas, para Pascual Carrión, eran «verdaderos sindicatos de cultivadores», que debían encargarse de la explotación racional de las tierras recibidas, con responsabilidad solidaria y mancomunada de todos sus miembros frente al pago de rentas y la devolución de créditos, para una recta administración de las mismas. En especial, continúa el ilustre ingeniero agrónomo, porque «se huyó, al redactar el proyecto, de pulverizar la tierra y alentar el individualismo de los agricultores, y se pensó en esta organización, verdadera clave de la reforma agraria». A este respecto, Edward Malefakis ha entendido que las comunidades no fueron propuestas por razones ideológicas, ya que tanto Flores de Lemus, como Carrión y Sánchez Román eran «expertos burgueses», sino como una alternativa técnica a la falta de preparación de los colonos campesinos para administrar sin ayuda las tierras ${ }^{26}$.

${ }^{26}$ Las citas del ingeniero agrónomo y del historiador norteamericano en CARRIÓN, P.: Op. cit., pp. 355-356, y MALEFAKIS, E.: Op. cit.. p. 209, respectivamente.

Hispania, LXIV/1, núm. 216 (2004) 267-324 
Esta consideración sobre el carácter «burgués» de dichos ponentes, además de un evidente prejuicio ideológico del propio historiador, pensamos que es notablemente desacertada, en especial, si valoramos otras manifestaciones del mismo Carrión para fundamentar la asignación de tierras para cultivar colectivamente, bien por dichas comunidades, bien por sindicatos campesinos (ambas posibilidades se reconocerían en el texto legal de la LBRA), o si tenemos en cuenta (algo ya se ha adelantado) las pocas pero muy relevantes intervenciones de Felipe Sánchez Román, tanto en el debate plenario del dictamen del PLBRA de abril de 1932, como en la discusión del proyecto de ley de «encartados» en la sesión de 18 de agosto de ese mismo año, tras el golpe fracasado del general Sanjurjo. Es también inadecuada por lo que se refiere a la justificación "técnica» de la entrega de las tierras a las comunidades, entre otras razones, por las manifestaciones hechas al hilo del debate parlamentario por los diputados especializados en la materia de que un cultivo rentable de las tierras de secano (mayoritarias en la presumible oferta de tierras expropiables) exigiría explotaciones de gran superficie y producciones de escala con el fin de rentabilizar su actividad, lo cual, ciertamente, no obedecía a una supuesta falta de preparación de los asentados, sino a razones de viabilidad técnica y económica (sin obviar la posible ignorancia o insuficiencia gestora de los campesinos beneficiarios). Por ello, tanto en esta ponencia de la CTA como en los restantes proyectos, hasta culminar en la propia LBRA, permaneció inalterable para las mencionadas comunidades campesinas un régimen opcional entre la explotación individual o la colectiva, de cara a rentabilizar las tierras en cultivo objeto de asentamiento.

La CTA introdujo dicho régimen opcional en la base $14^{\mathrm{a}}$, para que las comunidades campesinas decidieran, por mayoría de votos de sus miembros, la forma de explotación individual o colectiva de los terrenos adjudicados en el acta de ocupación, prescribiendo explícitamente la explotación directa por los asentados, y no autorizando, por tanto, las formas de explotación mediante aparcerías, arrendamientos, censos, etc ${ }^{27}$.

Finalmente, por lo que se refiere al régimen de excepciones, el proyecto eximía de ocupación temporal a todos los bienes comunales de los municipios, a los bienes del Estado y de la provincia, y a los de los pueblos que «no tengan el carácter de propiedad privada o de bienes patrimoniales», según lo prescrito por la última base, la decimoctava. Además, se exceptuaba la ocupación, pero no el gravamen fiscal sobre el exceso de renta catastral (o de líquido imponible), en las tierras dedicadas a explotación forestal y a pastos, siempre que no

27 Paloma Biglino ha hecho especial hincapié en cómo los socialistas, durante todo el período republicano se mantuvieron firmes en la defensa tanto del principio de nacionalización del suelo como de la explotación colectiva de la tierra, pero que cedieron respecto a la posibilidad de optar por la explotación individual, eso sí, sin admitir la idea del reparto conducente a la entrega de parcelas en propiedad, "dado que esta sería la única solución posible en algunos casos por la mentalidad individualista de los campesinos" (BIGLINO, P.: El Socialismo Español y la Cuestión Agraria (1890-1936), Madrid, 1986, pp. 350-351). 
fueran «susceptibles de un cultivo permanente»; por último, a instancia de parte interesada, «aquellas fincas que por su ejemplar explotación sirvan como tipo de perfección técnica y económica». Este régimen de excepciones a la ocupación temporal, también para la expropiación después, va a perdurar, con escasas variaciones, en todos los proyectos de reforma posteriores hasta la aprobación de la Ley de 1932, con la salvedad de que las tierras dedicadas a explotación forestal o a dehesas de pasto y labor, tampoco quedarían exentas, cuando procediera aplicar la causa expropiatoria por motivo de "presión social», es decir (se reitera), cuando el propietario de este tipo de tierras disponía de una superficie excesiva en términos relativos respecto a la total del término municipal, y, por ello, se interpretara que podía cuestionar la independencia política y socio-económica de dicho municipio.

El proyecto de la CTA, en resumen, configuró un plan de reforma agraria que iba a operar para el futuro como un modelo estructurado en diversos apartados (retroactividad; cupos de asentamientos, instituciones ejecutivas, censos de campesinos, Comunidades, tierras afectadas, excepciones, etc.), que gravitaría sobre todas las propuestas posteriores (su influencia, en concreto, en el PLBRA de Domingo sería motivo de un relevante debate político entre Sánchez Román y el radical Álvarez Mendizábal), y en el que, en definitiva, podemos enfatizar los presupuestos esenciales que a continuación se enumeran, condicionados todos ellos, por la utilidad social, como causa legitimadora de la acción intervencionista del Estado, a la que se remitía expresamente la ponencia propuesta por la CTA:

$1^{\circ}$ La urgencia y gravedad del paro campesino, como condicionante principal, además de por la conciencia de la situación de miseria y hambre vivida en el campo por los sectores sociales más desfavorecidos, por la fuerte convicción existente entre algunos de los ponentes de la CTA (el propio presidente Sánchez Román) de la amenaza real de un levantamiento campesino, sobre todo en Andalucía, que abriría un proceso, quizá imparable, de ocupaciones de fincas y serios conflictos de orden público estimulados, sobre todo, por los anarcosindicalistas de la CNT (también el entonces Ministro de la Guerra, Manuel Azaña, compartió esta misma preocupación, como vimos).

$2^{\circ}$ La opción preferente por el régimen de ocupación temporal en detrimento de la expropiación que, ligada tanto al grave desempleo jornalero, como al temor a las revueltas campesinas, implicaba una pronta puesta en marcha del programa de asentamientos, sin necesidad de contar con los presumiblemente cuantiosos recursos económicos (con los que no contaba el Estado, por otra parte) que demandaría el proceso expropiatorio sobre la base de un siste$\mathrm{ma}$ indemnizatorio equitativo.

$3^{\circ} \mathrm{La}$ voluntad de aplicar la reforma agraria en todo el territorio de la República, a pesar de la implantación prioritaria de los asentamientos en zonas específicamente delimitadas. Como se confirma por la aprobación de un im-

Hispania, LXIV/1, núm. 216 (2004) 267-324 
puesto especial sobre la renta catastral de las fincas rústicas, para todos los propietarios terratenientes del país, y, muy especialmente, por el criterio adoptado de la unidad-propietario a la hora de acumular todo el conjunto de propiedades rústicas de un mismo titular dominical en todo el territorio nacional. De este modo, se computaba el total de hectáreas de superficie poseídas por cada propietario, para determinar, en concreto, tanto las tierras afectadas por la ocupación, como los excesos de renta catastral objeto del gravamen especial señalado.

$4^{\circ}$ Un selectivo intervencionismo estatal, dirigido no tanto a estimular procesos de nacionalización de la tierra afectada (ocupada temporalmente a corto plazo, sin descartar una posible expropiación futura), como a establecer un marco jurídico coactivo que regulara las nuevas relaciones contractuales impuestas (explotación de la tierra ocupada con la contraprestación del pago de un canon), sin que se produjera ninguna subrogación por parte del Estado en los derechos y obligaciones del titular dominical. Este presupuesto específico de la ponencia sería rechazado en absoluto por parte de los vocales socialistas de la Comisión, porque una de sus reivindicaciones fundamentales pasaba por la nacionalización de la tierra afectada, en el sentido de que la propiedad expropiada (u ocupada definitivamente) quedaba en poder del Estado, transmitiéndose exclusivamente a los campesinos asentados el derecho de uso y explotación sobre la tierra, en otras palabras, el dominio útil.

$5^{\circ} \mathrm{Un}$ contundente ataque tanto al propietario terrateniente absentista (ausencia de cultivo, deficiencias en la explotación, arrendamiento sistemático) como al latifundista (concentración de la propiedad), en beneficio del cultivador directo, sin que se discriminase, además, respecto a la legitimidad o no de los derechos dominicales sobre la tierra (origen señorial, posible usurpación de bienes rústicos comunales, adquisición irregular de bienes desamortizados, etc.), como sí harían, por el contrario, a los efectos de una posible expropiación (indemnizable o no según los casos), los proyectos posteriores.

$6^{\circ}$ Finalmente, sólo resta hacer hincapié especial en el mencionado rechazo de los vocales socialistas a la ponencia, porque, como hemos visto, sus reticencias hacia el sistema de ocupación temporal frente a la expropiación por ellos propugnada, que quedaba diferida en el tiempo, y la voluntad manifestada por el Pleno de la CTA de no proceder a ninguna nacionalización de la tierra a corto plazo, no sólo fueron meras razones básicas para fundamentar, formalmente, su voto particular a la totalidad de la ponencia, sino un serio aviso de fuerte oposición para el futuro. Aviso que sería comprendido por los restantes miembros republicanos de la coalición gubernamental, en la medida en que la ponencia sería rechazada (a pesar de la feliz acogida jurídico-positiva que tanto su estructura como su desarrollo, tuvieron dentro de los siguientes proyectos y dictámenes sobre la reforma agraria, e incluso, en la propia LBRA de 1932), la alternativa de la expropiación quedaría consolidada de inmediato, y una calculada ambigüedad en algunos de sus presupuestos fundamentales (criterio de unidad finca versus unidad-propietario, exención mayor o menor de las fincas 
del propietario cultivador directo, acceso o no a la propiedad de la tierra objeto de asentamiento a medio plazo, centralización más o menos intensiva de las instituciones ejecutivas de la reforma, etc.), impregnaría las sucesivas propuestas en la materia, y, en particular, la siguiente, elaborada ya por el propio poder ejecutivo (con relevante protagonismo del Ministro de Justicia, el socialista Fernando de los Ríos), y defendida por el Presidente de Gobierno, Niceto Alcalá-Zamora y Torres, en el seno de las recién elegidas Cortes Constituyentes, en el mes de agosto de 1931.

\section{LA COMISIÓN MINISTERIAL Y EL SEGUNDO PROYECTO DE REFORMA AGRARIA}

El proyecto de la Subcomisión de latifundios, una vez aprobado por el pleno de la CTA, fue presentado al Gobierno el día 15 de julio ${ }^{28}$, siendo convocados para informar como ponentes Felipe Sánchez Román (jurista), Pascual Carrión (ingeniero agrónomo) y Antonio Flores de Lemus (economista), en el Consejo de Ministros del 23 de julio. Dos días antes, el 21 de julio, el Gobierno estuvo debatiendo por primera vez sobre el proyecto, surgiendo en seguida fuertes discrepancias sobre el mismo. En este sentido, el presidente Alcalá-Zamora escribiría en sus Memorias - reelaboradas de nuevo entre 1940 y 1946, en el exilio argentino-, con el lenguaje barroco y afectado que le caracterizaba, que se opuso, en particular, a las ocupaciones temporales propugnadas por la CTA, porque: «Prevaleció sobre la parcelación definitiva una nueva y desordenada estabilidad meramente posesoria, con nombre semitécnico de 'asentamientos ', indicador de situaciones inciertas, propensas a iniciativas asaltantes, legalizador de violencias mayores que las roturaciones arbitrarias, y con escaso amparo de indemnización ${ }^{29}$. Además, le puso otras objeciones, entre las cuales, según Azaña, la más importante fue que la gran propiedad terrateniente no era objetivo primordial para el reparto de tierras. Por su parte, el Ministro de Trabajo, Largo Caballero, tampoco aprobó el proyecto, y el propio Azaña reconoció en su diario, que no lo había leído y que el único conocimiento que tenía procedía de unas someras explicaciones que le había dado Sánchez Román. En la sesión del Consejo de Ministros del día 23 de julio ${ }^{30}$, sería, precisamente, Alcalá-Zamora el que planteó las dudas e hizo diversas preguntas a los ponentes de la CTA, y Flores de Lemus, en particular, el que respondió a ellas, «algunas veces, a media voz, con un tono detaché y algo irónico", sin que el resto de los miembros del Gobierno hicieran observaciones. Sólo Largo Caballero matizó si no se iba a llegar a la «nacionaliza-

\footnotetext{
${ }^{28}$ CARrión, Pascual: La reforma agraria de la segunda república y la situación actual de la agricultura española, Barcelona, 1973, p. 115.

29 AlCALÁ-ZAmora, Niceto: Memorias, Madrid, reedición 1998, p. 213.

${ }^{30} \mathrm{La}$ reunión con los tres ponentes de la CTA se celebró en el ministerio de Trabajo (GARCía DE BLAS, A.: «Don Antonio Flores de Lemus y la Comisión Técnica Agraria» en Hacienda Pública Española (Madrid) 42-43 (1976), p. 301).

Hispania, LXIV/1, núm. 216 (2004) 267-324
} 
ción, sin indemnización, de las tierras procedentes de los antiguos señoríos», a lo que la Comisión contestó, siempre según Azaña, que sería la ley Agraria la que, más adelante podría regular esta materia, ya que con el decreto propuesto por la CTA, sólo se aplicaría un programa de medidas provisionales ${ }^{31}$.

Pascual Carrión, por su parte, se ha referido a la oposición de los «republicanos de derechas", y en especial a la de los radicales de Lerroux, porque el proyecto les parecía "demasiado avanzado", frente a la de los socialistas, para quienes, por el contrario, era "conservador", precisamente porque no se llegaba a la expropiación de las fincas y los campesinos asentados quedaban en una situación de inestabilidad ${ }^{32}$.

En un artículo publicado, pocos meses después, en el primer número de Economía Española (la revista de la patronal Unión Económica) de enero de 1933, el especialista agrario Fernando Campuzano y Horma analizaba los diversos proyectos de reforma agraria propuestos hasta la aprobación de la Ley de 1932, afirmando respecto del presentado por la CTA, en concreto, que:

«La fuerza destructiva de este proyecto queda sintetizada con lo que acabo de exponer. Injusto, por reducir la propiedad rústica; injusto, por imponer sobre ella un gravamen desmedido; injusto, por la ocupación temporal; injusto, por admitir una expropiación sin compensaciones ni garantías festo no se corresponde con lo regulado en el proyecto, como ya sabemos, porque sobre la expropiación sólo había una remisión a una futura ley de reforma agraria o a otras especiales, para el supuesto de que los asentamientos temporales se convirtieran en definitivos (párrafo segundo, base $7^{a}$ )]. Además de esto, desencajado del régimen económico nacional, puesto que se formaba con la propiedad agrícola una cuña socialista, que a golpe revolucionario había de incrustarse en el régimen capitalista español, y, por fín, de un pronunciadísimo sabor soviético, que se incubaba en estas Comunidades de campesinos» ${ }^{33}$.

En este mismo sentido, el diputado radical Álvarez Mendizábal, durante la discusión del PLBRA de Domingo en el Congreso de los Diputados, hizo una alusión muy significativa sobre esta ponencia de la CTA declarando que: «No puede darse un caso de nacionalización, ni de socialización de la tierra más puro, más absoluto; es el régimen agrario, la reforma agraria de Rusia, sólo que

${ }^{31}$ La información sobre la primera discusión gubernamental, de 21 de julio de 1931 , y la referente al Consejo de Ministros, de dos días después, en AZAÑA, M.: Op. cit., pp. 83 y 90, Anotaciones de 21 y 23 de julio de 1931, respectivamente. En la acertada opinión de Eduardo Espín, la postura de Azaña era contraria al proyecto porque, en el momento de la discusión gubernamental había levantado "expectación e intranquilidad" en los medios agrarios, y porque tanto el proyecto de la CTA como el posterior de la comisión ministerial le parecían «excesivamente radicales e impracticables» (ESPÍN, Eduardo: Azaña en el poder. El partido de Acción Republicana, Madrid, 1980, p. 214).

32 CARrión, P.: La reforma... Op. cit., p. 118.

33 Campuzano y Horma, F.: «Ensayo crítico sobre la Reforma Agraria» en Revista Nacional de Economia (Madrid) 1 (1933), pp. 47-48. 
sin revolución». Sin embargo, como ya hemos visto, dicha ponencia no incluyó ningún principio nacionalizador, ni socializador, porque la tierra sólo era objeto de ocupación temporal, no de apropiación, aunque las condiciones del asentamiento ciertamente fueran imperativas para los propietarios afectados. Esta matización tan evidente, así la hizo constatar en su réplica a Álvarez Mendizábal el propio Felipe Sánchez Román, que había sido interpelado anteriormente por este destacado diputado radical en dicho debate plenario ${ }^{34}$.

El radical-socialista Marcelino Domingo, entonces Ministro de Instrucción Pública, —en el primer Gobierno constitucional de Azaña, de 16 de diciembre de 1931, sería nombrado titular de la nueva cartera de Agricultura, Industria y Comercio, siendo responsable de la presentación del PLBRA que acabaría siendo promulgado como ley el 15 de septiembre de 1932 - afirmaría pocos años después, que la postergación de la ponencia propuesta por la CTA mediante decreto fue un error del Gobierno, porque: «Debió constituirse inmediatamente el Instituto de la Reforma Agraria, según las bases del mismo Decreto, y aplicar aquélla en toda su intensidad. (...) Este error es una de nuestras grandes experiencias» ${ }^{35}$.

La tercera sesión que el Gobierno dedicó a la discusión del proyecto se celebró el 10 de agosto, y en ella los ministros acordaron rechazar el sistema de ocupación temporal regulado por la Base $7^{\mathrm{a}}$, porque, según testimonio de Azaña, «no atenuaba la expropiación» y porque la temporalidad de las ocupaciones no podía contentar a los campesinos. En dicha sesión, los ministros discutieron nuevos planteamientos sobre el alcance de la reforma agraria, optando, en definitiva, por la creación de una comisión ministerial para que elaborase un nuevo proyecto. Al respecto, el Ministro de la Guerra dejó constancia igualmente de su desinterés al escribir, en su diario, que se había opuesto en el Consejo a participar en una comisión ministerial encargada de la elaboración de un nuevo proyecto de reforma agraria, contestando al Presidente Alcalá-Zamora, que le había invitado a formar parte de ella, que dicho proyecto "no me dice nada». No obstante, Azaña afirmó que: «Esto es exagerado, y luego he sentido haberlo dicho tan crudamente», pero es que, continuaba, "el proyecto va retrasado con respecto a los acontecimientos, y que dado por decreto hace tres meses, quizá hubiera conseguido lo que se propone» ${ }^{36}$. Con el rechazo al proyecto de la CTA por parte del Gobierno y su inmediata disolución, se materializaba el triunfo de la intensa campaña de protestas puesta en marcha por los grupos de

${ }^{34}$ La declaración que se cita de Álvarez Mendizábal, en DSCC, núm.178, de 7 de junio de 1932, p. 6.060. Esta manifestación crítica la hizo en un cruce dialéctico que tuvo con el diputado liberal de la ASR, a quien consideraba máximo responsable de dicha ponencia, por haber sido presidente de la CTA que la patrocinó.

35 Domingo, M.: Op. cit., p. 221.

36 AZAÑA, M.: Op. cit., pp. 149-152, Anotación de 10 de agosto de 1931. Juan Velarde ha interpretado el rechazo del proyecto de la CTA y la creación de dicha comisión ministerial como un «golpe de timón a la derecha, muy fuerte» (VELARDE, Juan: «Talantes de políticos republicanos, clave ante la Reforma Agraria» en Anales de Economía (Madrid) 14 (1972), p. 20).

Hispania, LXIV/1, núm. 216 (2004) 267-324 
presión terratenientes en favor de que fueran las Cortes quienes regulasen en exclusiva todo lo referente a la reforma agraria. $Y$ es que como sostuvo el jurista y también vocal de la CTA, Mariano Granados, «gran parte de la opinión española, poco acostumbrada al funcionamiento de los consejos técnicos, recibió el proyecto de la comisión con rostro mal agestado y además iracundo» ${ }^{37}$.

Haciéndose eco de las reacciones airadas suscitadas en su momento por el proyecto de la CTA, Felipe Sánchez Román declaró en las Constituyentes al hilo de un intercambio dialéctico (ya referido) con el diputado radical Álvarez Mendizábal que:

«Cuando por quebranto de aquel compromiso de secreto, alguien, que yo no sé quién, publicó aquel dictamen y se dió a conocer a la opinión, ocurrieron dos hechos, de los cuales puedo dar un testimonio bastante preciso. Desde luego, uno notorio: la ofensiva radical de los grandes terratenientes contra todo lo que aquel dictamen pudiera representar. Pero, en cambio, hay otro hecho que seguramente S. S. no conoce y que yo, por un accidente que no puedo eslabonar con ninguna causa determinada o concreta, he venido a saber, y es que aquella misma odiosidad que despertó dicho dictamen en las clases terratenientes y conservadoras, la despertó también en los elementos más extremistas de la política rebelde [alusión implícita a los anarcosindicalistas], hasta el punto de que sus jefes, las cabezas pensantes de estas extensas organizaciones, se reunieron con alarma a la vista de aquel dictamen salido a conocimiento del público en general y acordaron combatirlo fundamentalmente, porque entendieron que si aquel proyecto se traducía en una disposición de aplicación inmediata, las regiones a que comprendía, Andalucía y Extremadura principalmente, iban a ser el sitio donde esas masas rebeldes y excitadas perdieran con más rapidez sus contingentes de hombres hambrientos. De modo es que cuando yo pude observar que la crítica venía con igual carácter irascible desde el plano de los propietarios terratenientes que desde el plano de las filas extremistas y rebeldes que han hecho una gestión política perfectamente marcada en Andalucía y Extremadura, no se puede figurar el Sr. Mendizábal, no se lo puede suponer, lo satisfecho que me quedé en mi conciencia»38.

En este sentido, Mercedes Cabrera ha hecho especial hincapié en cómo la reacción de los grandes terratenientes, dirigida a evitar la aprobación de la reforma por decreto, les llevó a realizar toda una serie de visitas a ministros y portavoces de los grupos parlamentarios, y a anunciar la convocatoria de una magna asamblea nacional para el 27 de julio con aquel objetivo fundamental. Dicha asamblea sería prohibida, pero «Alcalá-Zamora prometió que la reforma no iría a la Gaceta como decreto»39. Por su parte, Edward Malefakis ha inter-

37 La cita del vocal de la CTA, en GRANADOS, Mariano: La Reforma Agraria en Europa y el Proyecto Español. Los métodos, los resultados, Madrid, 1932, p. 103.

${ }^{38}$ DSCC, núm. 178, de 7 de junio de 1932, p. 6.062.

39. CABrera, Mercedes: La patronal ante la II República. Organizaciones y estrategia. 1931-1936, Madrid, 1983, pp. 176-177. 
pretado el proyecto de la CTA como un ataque indiscriminado y muy duro contra la gran propiedad rústica, al insistir en que el criterio de ocupación de las fincas se fundamentaba exclusivamente en el tamaño de la superficie y el volumen de riqueza obtenida, sin que se hiciera diferencia alguna respecto a la condición nobiliaria o no de sus propietarios, o a la explotación directa o indirecta de éstos. Sin embargo, no deja de reconocer que la ponencia de la CTA era "técnicamente excelente», porque entre otras razones abordaba con urgencia el problema de grave paro campesino afectando «solamente a unos cuantos miles de los mayores terratenientes». Pero el carácter técnico e independiente, en su opinión, de los ponentes del proyecto, influyó en que éste no fuera aprobado, precisamente porque «la Comisión no representaba ningún partido». No obstante, para este historiador «la causa principal de su fracaso estribó en el carácter excesivamente radical que su proyecto tenía para la mayoría de los partidos representados en el Pacto de San Sebastián ${ }^{40}$.

Las valoraciones sobre el carácter técnico e independiente de los ponentes, o los «errores tácticos» cometidos y «la altivez de su comportamiento», ofendiendo sobre todo a los socialistas, que realiza Malefakis, requieren ciertas matizaciones. En efecto, la condición independiente y exclusivamente técnica que este historiador atribuye a los principales responsables de la ponencia, como uno de los factores determinantes de su rechazo, consideramos que es una apreciación errónea, porque entre los miembros de la subcomisión encargada de su elaboración, había representantes de partidos y opciones políticos, no sólo extragubernamentales (los pertenecientes a la ASR, como Díaz del Moral o el propio Sánchez Román), sino también de los que formaban parte de la coalición en el Gobierno como, por ejemplo, los socialistas Lucio Martínez Gil (que era, entonces, secretario general de la FNTT de la UGT, fundada en abril de 1930, y adherido a la corriente «besteirista» del PSOE), Juan Morán o Francisco Zafra (los cuales, si bien presentaron un voto particular a la totalidad de la ponencia, como sabemos, por discrepancias de fondo, consiguieron, no obstante, incorporar al texto de la ponencia algunas enmiendas significativas, sobre retroactividad, afectación de tierras de regadío, etc.); o como el republicano de izquierda, Adolfo Vázquez Humasqué, correligionario de Azaña en su partido AR. El mismo Pascual Carrión, por su parte, se había presentado a las elecciones generales de junio por Sevilla, integrando una candidatura «andalucistasocialrevolucionaria» junto a, entre otros, Ramón Franco, Blas Infante y José Antonio Balbontín ${ }^{41}$.

Descartada finalmente la ponencia de la CTA en el Consejo de Ministros de 10 de agosto de $1931^{42}$, en la misma sesión se decidió asumir la iniciativa de la

\footnotetext{
40 Malefakis, E.: Op. cit., pp. 210-212.

${ }^{41}$ TUNÓN DE LARA, Manuel: Tres claves de la Segunda República. La cuestión agraria, los aparatos del Estado, Frente Popular, Madrid, 1985, pp. 45-46.

42 «El proyecto de la Comisión Técnica tenía, sin duda, un contenido realmente revolucionario (...) de haberse aplicado, habría colmado razonablemente las reivindicaciones de los trabajadores y

Hispania, LXIV/1, núm. 216 (2004) 267-324
} 
elaboración de un nuevo proyecto de reforma agraria, para lo que se constituyó una Comisión Ministerial encargada de su redacción bajo el patrocinio directo del Presidente del Gobierno, Niceto Alcalá-Zamora. Ya conocemos el desinterés de Manuel Azaña y su negativa a formar parte en dicha comisión, por lo que serían Fernando de los Ríos y el propio Presidente los responsables de la redacción del proyecto. En efecto, Azaña anotó en su diario que, en esta misma sesión del Consejo de Ministros, además de rechazar las ocupaciones temporales propuestas por la CTA, se decidió crear una Comisión Ministerial para que se encargara de redactar los "laboriosos» acuerdos adoptados en la reunión sobre la reforma agraria: expropiación de las tierras de origen señorial, pago de indemnizaciones mínimas, etc, haciendo especial referencia al clima de intranquilidad y alarma que «los proyectos de reforma» habían provocado entre los «pequeños terratenientes» $y$ «la clase media» ${ }^{43}$.

Una vez concluido el nuevo proyecto, fue presentado por Alcalá-Zamora, a las Cortes Constituyentes como Proyecto de ley de Bases para la reforma agraria, y defendido por él mismo en la sesión plenaria del 25 de agosto de 1931. El proyecto había sido aprobado por el Gobierno tres días antes, de acuerdo con el testimonio de Azaña, que anotó en su diario lo siguiente: "despachados los asuntos corrientes, se lee y es aprobado el proyecto de ley Agraria, al que he prestado poca atención» ${ }^{44}$. El proyecto estaba firmado por Alcalá-Zamora y los ministros de Justicia, Fernando de los Ríos; de Fomento, Álvaro de Albornoz; de Trabajo y Previsión, Francisco Largo Caballero; y por el de Economía Nacional, Luis Nicoláu D'Olwer ${ }^{45}$. Constaba de 24 bases y en su preámbulo se declaraba expresamente que: "Ha sido propósito inicial y constante del Gobierno, precisamente por haber formado parte esencial del programa de la revolución, el acometer la reforma agraria». En la misma introducción, se reconocía explícitamente el grave problema de desempleo de los jornaleros sin tierras, y la estrecha conexión existente entre la necesidad de transformar la estructura de la propiedad terrateniente y la consolidación del régimen democrático republicano. En este sentido, se afirmaba que:

\footnotetext{
habría alterado sustantivamente la estructura social agraria. Desde luego habría terminado con el latifundio» (PÉREZ YRUelA, Manuel: "La reforma agraria en España" en Cuadernos de Historia 16 (Madrid), 239 (1985), pp. 13-14). Abundando en estas matizaciones favorables sobre el anteproyecto de la CTA, Jordi Palafox ha resaltado «las innumerables ventajas» que el mismo tenía, «para iniciar la erradicación del atraso agrario que dominaba las zonas de latifundio, hacer descender el apoyo de gran parte de los jornaleros a las propuestas de los dirigentes de la CNT y, al mismo tiempo, limitar el poder de los grandes propietarios» (PALAfOX, J.: Op. cit., p. 213).

${ }^{43}$ AZAÑA, M.: Op. cit., pp. 149-150, Anotación de 10 de agosto de 1931.

${ }^{44}$ AZAÑA, M.: Op. cit., p. 191, Anotación de 22 de agosto de 1931.

45 Dicho proyecto está publicado en DSCC, núm. 26, de 25 de agosto de 1931, en el Apéndice $9^{\circ}$. Una copia original del documento, con las firmas legibles del Presidente de Gobierno y los ministros mencionados, se encuentra en Archivo Cortes, Congreso de los Diputados, Serie General, Legajo 543, Exp. 2.
} 


\begin{abstract}
«El hambre de tierra, agudizada en nuestro pueblo singularmente desde la desamortización, necesita ser aplacada por la República, ya que la actual constitución jurídico-territorial de España, caso de perdurar, invalidaría el esfuerzo político llevado a cabo por la Nación, pues equivaldría a dejar subsistente la estructura económica que hace imposible la efectividad de una democracia» ${ }^{46}$.
\end{abstract}

Así mismo, se enfatizaba la valiosa contribución de la ponencia de la CTA que con tanta «competencia y acierto» había desempeñado su cometido, hasta el punto de que, como se reconocía, el proyecto gubernamental continuaba en lo sustancial con gran parte de los presupuestos y orientaciones en ella propugnados (órganos preparatorios y ejecutores de la reforma, limitaciones a la propiedad terrateniente por razón de superficie y volumen de riqueza, gravamen especial sobre la renta catastral de los bienes, rústicos, alternativa entre régimen de explotación individual o colectiva, ámbito territorial de aplicación y provincias designadas, etc.), por la «fundamental coincidencia entre el criterio del Gobierno y el de la ponencia». Muy crítico, precisamente, con esa línea de continuidad entre el proyecto de la CTA y los proyectos y dictámenes sucesivos, Felipe Sánchez Román manifestó en las Constituyentes en la discusión plenaria de totalidad del PLBRA de Domingo que:

"Aquel dictamen creado para una finalidad concreta [afrontar el grave paro campesino], instrumentado en instituciones especialísimas para cubrir solamente el propósito con que había sido concebido, propósito eventual, provisorio, urgente, inminente, aquel dictamen ha tenido la fatal desgracia de sobrevivirse (...) Y esto tiene una alta gravedad; tiene la gravedad de que aquel proyecto o dictamen fracasó en el concepto de la opinión pública y fracasó en el criterio del Gobierno, $\mathrm{y}$, sin embargo, por un juego misterioso de fuerzas de arrastre, ese dictamen vuelve a renacer (...) Y esto yo creo que no puede ser (...) [porque] no podía jamás tener la pretensión de substituir a la auténtica reforma agraria del porvenir» ${ }^{47}$.

A pesar de la sustancial coincidencia, el preámbulo del PLBRA, no obstante, explicitaba la necesidad de abordar la expropiación definitiva de las tierras afectadas, y no la ocupación temporal defendida por la CTA, por razón de «asentimiento social», seguridad del tráfico jurídico y refuerzo del crédito territorial frente a la incertidumbre de los asentamientos provisionales, «atacando, desde luego, como propiedades de origen menos legítimo y de coacción social y política más evidente y dañosa, los dominios heredados de título señorial». En este sentido, Alcalá-Zamora, en su intervención para explicar el proyecto, matizaría que: "aspirando el Gobierno a dejar exenta de la reforma la propiedad mediana cultivada directamente por sus dueños, acometió, en cambio, de fren-

${ }^{46}$ La redacción del preámbulo y de parte del articulado del proyecto se debió a Fernando de los Ríos, según manifestó Alcalá-Zamora en la presentación del mismo al agradecer expresamente la intervención del ministro socialista (DSCC, núm. 26, de 25 de agosto de 1931, p. 577).

47 DSCC, núm. 175, de 1 de junio de 1932, p. 5.950.

Hispania, LXIV/1, núm. 216 (2004) 267-324 
te, resuelta, decididamente la lucha, contra la propiedad desmesurada, señaladamente si su origen era el título señorial» ${ }^{48}$.

A continuación iniciamos el estudio del PLBRA de agosto de 1931 dejando de lado todos aquellos aspectos idénticos a los de la ponencia de la CTA (retroactividad, asentamientos, provincias de aplicación, organismos ejecutivos, etc.). Entre las novedades destacables del proyecto, por ejemplo, se recomendaba la constitución de una Junta Local por cada partido judicial, en vez de por cada municipio, a no ser que su extensión territorial o su diversidad aconsejara la creación de una Junta en el mismo. Dentro de la ofensiva que las patronales agrarias desarrollaron para combatir el PLBRA una de las estrategias adoptadas fue el envío de decenas de informes y documentos a la CRA, aprovechando la apertura de un plazo (hasta el 10 de septiembre de 1931), otorgado por ésta, en su primera sesión de 27 de agosto de 1931, para recepción de iniciativas de entidades oficiales y particulares sobre dicho proyecto. Pues bien, entre los aspectos críticos más relevantes de los informes allí recibidos, sobresalió, sobremanera, el rotundo y casi unánime rechazo a las Juntas Locales, por considerar que el sistema basado en ellas, tal y como proclamaba el Informe de la Asociación de Agricultores de España, de 9 de septiembre de 1931, «es peligroso, de complicada organización de difícil vigilancia y fracasado en las reformas extranjeras», además de que eran "propicias a convertirse en instrumento pasional y de caciquismo político" ${ }^{49}$.

El proyecto gubernamental de reforma agraria, con una redacción, sin duda, más confusa e intrincada que la de la ponencia de la CTA, declaraba expropiables por causa de utilidad social (base $7^{a}$ ) todas las tierras «en el territorio de la República», que excedieran de los límites de superficie, según cultivos, establecidos en la base $5^{\text {a }}$ (no se matizan los topes de superficie a libre disposición de sus propietarios, porque son los mismos de la ponencia de la CTA). Así mismo, declaraba sujetas a gravamen o recargo tributario, todas las tierras cuya renta catastral (el líquido imponible, en su caso), excediera de 10.000 pesetas. Los excesos de renta catastral gravados eran exactamente iguales que los de la ponencia, pero variaban los tipos aplicados en los tramos intermedios de los umbrales de renta, de acuerdo con la escala progresiva de la base sexta. Esta escala reducía en un $5 \%$ los tipos de gravamen de la CTA (20\% y $30 \%$ respectivamente) para los dos umbrales intermedios de exceso de renta catastral comprendidos entre 20.001 y 40.000 pesetas (véase supra Cuadro 1 ).

${ }^{48}$ DSCC, núm. 26, de 25 de agosto de 1931, p. 573.

$49 \mathrm{El}$ acta de la primera sesión de la CRA, de 27 de agosto de 1931 (y de todas las celebradas durante su existencia), en Archivo Cortes, Congreso de los Diputados, Serie General, Legajo 543, Exp. 1, y el informe citado de dicha asociación, en Archivo Cortes, Congreso de los Diputados, Serie General, Legajo 544, Exp. 1, Doc. $N^{\circ} 24$. Una verdadera avalancha de documentos de sociedades y corporaciones agrícolas y de telegramas e instancias en favor y en contra, tanto referidos a este proyecto como al de Marcelino Domingo de marzo de 1932, inundaría a dicha comisión parlamentaria,. En el archivo del Congreso de los Diputados se encuentran hasta un total de 137 informes y documentos reunidos en el expediente núm. 1 del legajo citado, junto a centenares de telegramas e instancias en su expediente núm. 3.

Hispania, LXIV/1, núm. 216 (2004) 267-324 
En la base $7^{a}$ se regulaba la posibilidad de establecer «concesiones en disfrute» en la misma clase de tierras expropiables, que venían a ser, en puridad, los asentamientos temporales de la CTA, en tanto no se hubieren decretado las expropiaciones definitivas. Esta figura jurídica de la «concesión en disfrute» era un tecnicismo "prestado" de la ley de Expropiación Forzosa, según Alcalá-Zamora, para quién «en vez de ocupación temporal, con esa incertidumbre de renta para el asentamiento, para la medida provisional habrá concesiones retribuidas, concesiones que, como el censo, son dos instituciones jurídicas que permanecen latentes ${ }^{50}$. En este sentido, las patronales agrarias insistirían en que estas concesiones no dejaban de ser los mismos asentamientos temporales propugnados por la CTA, calificados de auténticas células comunistas en diversos informes publicados durante el mes de septiembre de 1931, gran parte de los cuales remitieron a la CRA, destacando, entre otros, el de la Asociación de Propietarios de Fincas Rústicas, el de la Asociación de Ganaderos y Olivareros, o el de la Liga Nacional de Campesinos. En particular, en el Informe de la Asociación Nacional de Olivareros de España, de 9 de septiembre de 1931, se decía, por ejemplo:

«(...) que el proyecto se ha fundamentado en un intento de nacionalización de la tierra, pero que como esta nacionalización no puede llevarse a cabo por los tranquilos cauces de la expropiación indemnizada, pues el Estado carece de los cuantiosos recursos económicos necesarios a estos efectos, el intento se convertirá en una ocupación gratuita de las citadas fincas, que por el pronto, representa una organización incipiente, comunista, ya que las juntas locales son verdaderos gérmenes de comunismo, por lo que al uso de la tierra respecta. No puede considerarse exagerado el que califiquemos de gratuita la ocupación ya que al propietario se le despoja de la acción del desahucio y no se le compensa ésta con otra garantía para el cobro de la hipotética renta, que durante el período de previa ocupación, a que venimos aludiendo parece asignársele en el proyecto» ${ }^{51}$.

La primera modificación de auténtica enjundia en el proyecto del Gobierno la encontramos en la Base $12^{\mathrm{a}}$, reguladora del orden de prelación para el asentamiento tanto de los concesionarios «en disfrute», en los casos de ocupación temporal, como de los adjudicatarios en los supuestos de expropiación definitiva. Este orden de preferencia se aplicaba de acuerdo con las reglas siguientes: $1^{\mathrm{a}}$ Tierras de origen señorial transmitidas por herencia. $2^{\mathrm{a}}$ Las de mismo origen dominical, pero transmitidas contractualmente desde hacía diez años. $3^{\mathrm{a}}$ Las tierras de posible regadío que, obligando la ley al mismo por existir un embalse de agua, no hubieran sido regadas; y las de regadío con aguas provenientes de obras hidráulicas que habían sido financiadas por la administración pública ${ }^{52}$.

so DSCC, núm. 26, de 25 de agosto de 1931, p. 574.

51 Archivo Cortes, Congreso de los Diputados, Serie General, Legajo 544, Exp. 1, Doc. No 23.

$52 \mathrm{Al}$ respecto de las plusvalías generadas por la realización de infraestructuras, Alcalá-Zamora matizó con acierto en el Congreso de los Diputados que en estas zonas de regadío «el aumento de

Hispania, LXIV/1, núm. 216 (2004) 267-324 
$4^{\mathrm{a}}$ «Las adjudicadas a la Hacienda, (...) y las correspondientes a la Iglesia $\mathrm{o}$ Comunidades religiosas pendientes de conmutación y las demás de personas sociales de interés público", salvo las pertenecientes a Fundaciones cuando su subsistencia dependiera de la conservación de las propiedades rústicas, aunque en este supuesto, se puntualizaba, "podrán ser sometidas al régimen de arrendamientos colectivos" $5^{a}$ Las tierras que excedieran de los límites de superficie establecidos por la base $5^{\mathrm{a}}$, pero sólo cuando hubieran estado arrendadas «desde hace diez o más años», con lo que se exceptuaba al propietario cultivador directo, cuando en la ponencia de la CTA sí que estaba afectado igualmente, si bien en último lugar.

Este orden de prelación y con él, los diferentes grupos por él establecidos, venía a su vez condicionado por la cláusula incorporada en el párrafo segundo de la misma base $12^{\mathrm{a}}$, que obligaba a afectar con preferencia las «fincas que correspondan a un solo propietario o a dos o más parientes en línea recta o hermanos, cuando tal propiedad exceda de la quinta parte de extensión en el término municipal respectivo". Esta circunstancia podía llevar a la Junta Central Agraria, cuando incidiera en «motivo de presión social sobre el vecindario», a decretar las concesiones, en su caso, o las expropiaciones definitivas, alterando dicho orden de preferencia e, incluso, a expropiar las tierras cultivadas directamente por sus propietarios que excedieran los límites regulados en la base $5^{a}$. Dentro de la amplia casuística expropiatoria incorporada a los diversos proyectos de reforma agraria, la causa por razón de "presión social» (a la que ya se hizo una breve referencia explicativa anteriormente), propuesta por primera vez en este proyecto, tendría una feliz acogida, con escasas variantes, en los restantes hasta ser incluida finalmente en el texto de la Ley de Bases. Así mismo, prescribía el PLBRA, podía ser objeto de expropiación la dehesa no susceptible de cultivo - que estaba, por ello, exenta por la base $24^{\mathrm{a}}$-, cuando, por su excesiva superficie, se pudiera interpretar que podía atentar contra la independencia social y política del municipio, con el fin de constituir el patrimonio común del mismo.

Otro presupuesto fundamental, también presente por primera vez, era el reconocimiento para los propietarios expropiados de una indemnización mínima, que fue objeto de controvertido debate y reñida votación entre los ministros. Así, Manuel Azaña escribió en su diario que:

«se resuelve en votación por mayoría, que se conceda una indemnización mínima a los señoríos. Han votado en contra de la indemnización Largo, Prieto, Ríos, Albornoz y Domingo [los tres ministros socialistas y los dos radicalsocialistas]. Yo no me he decidido, porque las observaciones de Nicoláu [el Minis-

valor del terreno es el resultado de una iniciativa y de un dispendio del Poder público, y en las que el principio de la expropiación venía ya aceptado por toda nuestra legislación» (DSCC, núm. 26, de 25 de agosto de 1931 , p. 574).

Hispania, LXIV/1, núm. 216 (2004) 267-324 
tro de Economía Nacional], sobre el influjo del despojo puro y simple en el crédito y en el cambio, me han hecho impresión» 53 .

Alcalá-Zamora, por su parte, se refirió a la cuestión en sus Memorias, afirmando que:

«Hubo en un consejo, celebrado en Hacienda, votación muy indecisa sobre tal problema y estuve a punto de ser vencido, ya que no concurríamos los doce miembros del gobierno y Albornoz como Domingo estaban de acuerdo con los tres socialistas. Apelé para ganar el voto decisivo al criterio profesional del técnico en la dirección de los Registros y así se obtuvo a favor de la indemnización el de Azaña, que prefería abstenerse y que lo emitió con salvedades de ulterior mudanza, nada acordes con la fijeza de opinión sobre un problema cuyos términos eran todos claros y conocidos» ${ }^{54}$.

En el debate plenario sobre el PLBRA de 1932, Sánchez Román se refirió a esta novedad del pago de indemnizaciones por causa de expropiación como a una "particularidad especialísima» que tenía el proyecto del Gobierno de Alcalá-Zamora, que, era en realidad, afirmó con sarcasmo,

«el mismo dictamen [de la CTA] con un injerto, el injerto de la expropiación, de una expropiación calculada de tal modo que la hectárea de terreno de secano, que en tiempo de normalidad podía venderse a 600 pesetas, poco más o menos, según aquel proyecto se indemnizaba a 2.100 pesetas. iY era ésta la única modificación sustancial que aquel proyecto tenía con respecto al dictamen! Aquel dictamen lo recogió la Comisión [parlamentaria] y lo modificó para que no resultase esta cosa verdaderamente asombrosa de que se hacía una Reforma agraria para beneficiar al propietario" 55 .

Para la regulación del procedimiento indemnizatorio el proyecto prescribía; en la base $13^{\mathrm{a}}$, la capitalización de las propiedades rústicas expropiadas a un tipo que difería según el origen señorial o no de las mismas, la forma de transmisión, etc. En primer lugar, la capitalización de las tierras señoriales heredadas se valoraba de acuerdo con el líquido imponible según un tipo variable en función de la fortuna total del propietario (del $5 \%$, hasta un millón de pesetas; del $6 \%$, en el exceso hasta tres millones; del $7 \%$, hasta cinco; del $8 \%$, hasta diez; y del $10 \%$, para más de diez millones). En su explicación al Parlamento, el Presidente del Gobierno había insistido, en este sentido, en la necesidad de un tratamiento discriminatorio para la propiedad señorial, en especial para la transmitida mortis causa, y así manifestó que:

${ }_{33}$ AZAÑA, M.: Op. cit., p. 150, Anotación de 10 de agosto de 1931.

${ }^{54}$ AlCALÁ-ZAMORA, N.: Op. cit.; p. 204.

ss DSCC, núm. 175, de 1 de junio de 1932, p. 5.951.

Hispania, LXIV/1, núm. 216 (2004) 267-324 
«para la propiedad no señorial, la capitalización de la renta auténtica, y cuando la renta auténtica se desconoce, un límite que no pueda pasar de la renta catastral capitalizada al 3 por 100 [un 3,5\% en realidad según el proyecto]; y, en cambio, para la propiedad señorial [insistimos en que se aplicaba sólo a la heredada], una escala progresiva de dureza (...) Para la propiedad señorial no admitimos prueba alguna contra la limitación del catastro o del amillaramiento» $\$ 6$.

En segundo lugar, las propiedades restantes (incluyendo, por tanto, las de origen señorial que hubieran sido objeto de transmisión contractual en los últimos diez años) se capitalizarían según el promedio de su renta en los últimos diez años, y, en su defecto, por tasación, no superior en ningún caso al 3,5\% del líquido imponible (a pesar de este tope máximo el sistema propuesto encarecía enormemente las indemnizaciones, de acuerdo con la denuncia realizada por Sánchez Román), hecha excepción del valor de las mejoras o los costes por instalaciones extraordinarias que fueran imputables al propietario, antes del 14 de abril de 1931. Al respecto, Pascual Carrión llamó la atención sobre el enorme coste económico de una capitalización de la renta con un tipo del 3\%, porque equivalía a treinta y tres veces el líquido imponible, y «se comprende que esta última tasación es en general elevada y no adecuada para una reforma agraria». Sin embargo, para Malefakis, como el precio de mercado de la tierra en 1931 era equivalente a treinta veces su líquido imponible, y éste no superaba la tercera parte de la renta real neta, un precio justo de mercado, en consecuencia, equivaldría a diez veces ésta; empero, como la propiedad nobiliaria era una de las "víctimas propiciatorias» de la reforma (junto a arrendadores y propietarios que no regaban), los «nobles iban a recibir solamente de diez a veinte veces [el líquido imponible] (...). En cambio, las víctimas de la reforma no pertenecientes a la nobleza recibirían el valor de mercado completo" ${ }^{57}$.

En cuanto a la forma de pago de las indemnizaciones, ésta se llevaría a efecto en metálico hasta un importe de 500.000 pesetas, y para cantidades superiores, mediante inscripciones de Deuda Pública interior al $4 \%$, con la salvedad adicional de que dichos títulos eran intransferibles, salvo herencia, e inembargables. Al respecto, la Asociación de Propietarios de Fincas Rústicas de España, en su Informe sobre el PLBRA, de 8 de septiembre de 1931, se declaró favorable a que:

«la Deuda que se emita no debe ser una Deuda especial, ni sufrir limitaciones respecto a élla el propietario expropiado. Una deuda especial equivale a escribir en el agua (...) debe ser una Deuda corriente (...) que entre en el comercio bursátil general al tipo de cotización, claro es, sin marca de origen, siguiendo las mismas

\footnotetext{
56 DSCC, núm. 26, de 25 de agosto de 1931, p. 575 . Tuñón de Lara ha interpretado este trato discriminatorio en perjuicio de la propiedad nobiliaria, como una conducta demagógica, «voluntaria o no, pero algo anacrónica en pleno siglo XX» (TUÑÓN DE LARA, M.: Op. cit., p. 49).

57 Ambas citas en Carrón, P.: La reforma... Op. cit., p. 119, y en MalefaKis, E.: Op. cit., p. 215 , respectivamente.
} 
vicisitudes de la ahora existente. Sólo esto será justo y sólo ésto indicará el debido respeto a la propiedad» 58 .

El fundamental principio de nacionalización de la propiedad rústica objeto de expropiación definitiva (que ya habían intentado incorporar los socialistas a la ponencia de la CTA), quedaba ya consagrado expresamente en el preámbulo del PLBRA, al escribir su redactor, Fernando de los Ríos, que:

«Alguna duda, aunque más limitada y leve, surgió también acerca de si, restablecida por el Estado a su favor la desmembración censal, característica frecuente de los grandes establecimientos territoriales, debía el gravamen ser o no redimible por el cultivador, y la decisión del Gobierno fué favorable a no fomentar aquella ilusión, manteniendo, como principio, la nacionalización del suelo adquirido por el Estado, al reemplazar en el dominio directo al antiguo y total dueño».

En consecuencia, dicho principio se incorporaba en el párrafo segundo de la base $21^{\mathrm{a}}$, al prescribirse que correspondía a la Asociación de cultivadores o a éstos individualmente, en su caso, el dominio útil de la finca adjudicada, con reserva expresa del dominio directo para el Estado, al que se le asignaba, por ello, un «canon irredimible» equivalente al 4,5\% de la indemnización debida al propietario expropiado. En su discurso de presentación del proyecto, AlcaláZamora matizó al respecto que la relación contractual entre el Estado y los asentados era la propia del censo, una «institución durmiente que reaparece» con la parcelación, declarando respecto a la nacionalización de la tierra expropiada, en particular, que:

«prevaleció el criterio de que ese censo jamás sea redimible, y, naturalmente, formaron la mayoría en este sentido los que habían formado la minoría en el otro problema de la propiedad señorial, porque se enamoraron, y tuvieron adhesiones bastantes para formar mayoría, del principio nacionalizador, es decir, socializador del suelo, mientras quedó en la minoría, sin desconocer el auge y el ambiente favorable de tal tendencia en la época moderna, un poco de simpatía al ansia, al ensueño del pequeño jornalero que desea convertirse en pleno propietario» $\$$.

En este sentido, en el Informe que emite la Cámara agrícola provincial de Córdoba y eleva a la Comisión Parlamentaria del proyecto de reforma agraria, de 8 de septiembre de 1931, se denunciaba esta base por estar «Muy en consonancia con la doctrina socialista». En contra de ésta, se reclamaba la entrega del dominio pleno de la tierra a los campesinos adjudicatarios, "con todas sus consecuencias, y por la mitad del valor de costo, pagado en 15 o 20 plazos anuales». No obstante, ya existía un antecedente ilustre de este principio de nacionalización de

58 Archivo Cortes, Congreso de los Diputados, Serie General, Legajo 544, Exp. 1, Doc. No 26.

59 DSCC, núm. 26, de 25 de agosto de 1931, p. 576.

Hispania, LXIV/1, núm. 216 (2004) 267-324 
la tierra, en concreto de los baldíos y bienes de manos muertas, en las propuestas planteadas a las Cortes en 1836, por Álvaro Flórez Estrada, el cual era partidario, además, de su entrega a los campesinos mediante «arriendo enfitéutico» con la contrapartida del pago de un canon al Estado ${ }^{60}$. En todo caso, para un coetáneo tan relevante en la materia como Juan Díaz del Moral (primer presidente de la CRA), en su obra clásica sobre las agitaciones campesinas andaluzas, escribiría que el reparto era la reivindicación más movilizadora entre los jornaleros por el deseo de éstos de convertirse en nuevos propietarios, ya que:

«no sólo las masas, sino casi todos sus elementos directores, entienden que el problema de la tierra se reduce, por abora, a la parcelación; casi ninguno confia en las aptitudes y la cultura de estos campesinos para la propiedad colectiva (...). Si fuera posible un plebiscito, el 999 por 1.000 se decidirían por la parcelación: tener cada cual su tierra, como tiene su azada, y emanciparse del salario, no servir a nadie» ${ }^{61}$.

Finalmente, en la última base del proyecto, la $24^{\mathrm{a}}$, se regulaba un significativo régimen de excepciones, de acuerdo en parte con lo propugnado por la CTA en su ponencia, es decir, que la normativa de la ley no se aplicaría, en primer lugar, a los bienes comunales y de propios de los Municipios, ni a los bienes estatales, ni a los de Provincia y pueblos que «no tengan el carácter de propiedad privada o de bienes patrimoniales». Pero, en segundo lugar, y aquí sí se planteaban importantes novedades, se exceptuaban de ocupación temporal y/o de expropiación (aunque, eso sí, manteniendo el gravamen especial sobre los excesos de renta catastral preceptuado en la base $6^{a}$ ), los bienes de la propiedad rústica: $1^{\circ}$ Que fueran cultivados directamente por sus dueños conforme a buen uso y costumbre ${ }^{62}$. $2^{\circ}$ Cuando sostuvieran una industria rural o agropecuaria y no se hallaren arrendados sistemáticamente, ni tampoco estuvieran afectados por lo regulado en el último párrafo de la base $12^{\mathrm{a}}$ (recordemos, la propiedad superior al $20 \%$ de la de todo el término municipal, cuando ejerce sobre el vecindario una presión social). $3^{\circ}$ Que estuviesen destinados a

60 El informe citado en Archivo Cortes, Congreso de los Diputados, Serie General, Legajo 544, Exp. 1, Doc. $\mathrm{N}^{\circ} 44$, y la información sobre el antecedente de Flórez de Estrạa, en Carrión, P.: Los latifundios... Op. cit., pp. 51-52.

61 DíAZ DEL MORAL, Juan: Historia de las agitaciones campesinas andaluzas. Córdoba (Antecedentes para una reforma agraria), Madrid, 1929, p. 377. En este sentido, la provincia de Jaén, según Luis Garrido, debió ser una excepción a la tesis del ilustre notario de Bujalance (Córdoba), ya que en ella "durante los años de la República hay una una opinión general favorable al colectivismo agrario", tanto por parte de la militancia de base como por parte de los dirigentes socialistas locales (GARRIDO, Luis: Colectividades agrarias en Andalucía: Jaén (1931-1939), Madrid, 1979, p. 13).

62 Esta excepción relativa a las fincas explotadas directamente a buen uso y costumbre por sus propietarios fue criticada por Pascual Carrión, porque consideraba atrasadas dichas costumbres y porque entonces no quedaría suficiente tierra para aplicar la reforma, ya que los límites establecidos de superficie eran mínimos y, tal y como afirmó, «se necesita tierra en cantidad no inferior a la indicada (CARrión, P.: Los latifundios... Op. cit., p. 364). 
explotación forestal o a pastos no susceptibles de cultivo permanente. $4^{\circ}$ Por último, y al igual que el proyecto de la CTA, el del Gobierno exceptuaba de expropiación, también a instancia de parte, las fincas de ejemplar explotación que sirvieran "como tipo de perfección técnica y económica».

Una vez explicado el proyecto de ley a las Cortes Constituyentes, AlcaláZamora insistió en el carácter urgente del programa de reforma agraria propuesto, por lo que solicitó a la Cámara que se eligiese con rapidez una Comisión Parlamentaria Especial encargada de conocer y tramitar dicho proyecto, encareciendo su importancia, porque, afirmó, la reforma agraria

«es la verdadera independencia política, la dignificación del campesino, la dignificación del obrero de la tierra, ésta es la revisión histórica de muchos siglos de injusticia señorial; (...) [ya que] sólo ensanchando la base de la estabilidad territorial de un pueblo se afirman sus Instituciones, se establecen intereses y se hace justicia que impide que quede en peligro un día el orden mismo que os interesa conservar».

Con estas palabras finalizaba su intervención y entregaba el proyecto de ley al Presidente del Parlamento, el socialista Julián Besteiro, tras agradecer la brillante colaboración prestada en su redacción a Fernando de los Ríos, manifestando expresamente que: "Hemos podido colaborar un Ministro socialista y un Presidente que está alejado del credo del marxismo» ${ }^{63}$.

El PLBRA de 22 de agosto de 1931, se caracteriza, en síntesis final, frente a la ponencia anterior de la CTA, por las siguientes notas diferenciadoras:

$1^{\text {a }}$ El programa de reforma agraria, asumido explícitamente como uno de los compromisos de la revolución, lo propone el propio Gobierno, mediante un proyecto de ley específico (si bien excesivamente vicario de la ponencia anterior), con lo que asume la autoría de su elaboración y la dirección política en su tramitación parlamentaria (presentación, defensa en el Pleno de las Cortes, y presumible control de la mayoría gubernamental dentro de la CRA a los efectos de la emisión del correspondiente dictamen de conformidad de dicho proyecto de ley).

$2^{\mathrm{a}} \mathrm{La}$ incidencia de la coyuntura política registra un vuelco considerable en la voluntad del Gobierno a la hora de impulsar la reforma (sobre todo en materia de plazos y control parlamentario por parte del poder legislativo), que refleja la creciente presión social de las intensas protestas de las patronales agrarias y un menor protagonismo, en contrapartida, de la valoración gubernamental sobre la amenaza de un levantamiento generalizado del campesinado sin tierras y/o un proceso masivo de invasiones de fincas. En consecuencia, quedaba descartada la posibilidad de aprobar la reforma por decreto ministerial, amparado en razones de urgencia y gravedad del paro jornalero, de acuerdo con la petición hecha por la CTA.

${ }^{63}$ DSCC, núm. 26, de 25 de agosto de 1931, p. 577. 
$3^{\text {a }}$ Se reitera en la exposición de motivos o preámbulo, la conexión jurídicopolítica entre la proyectada transformación de la estructura de la propiedad terrateniente y la consolidación del régimen republicano, con un énfasis especial en la esperanza de crear un amplio sector social de partidarios y simpatizantes de la República dentro del campesinado más desfavorecido secularmente, al que, no obstante, se impide convertirse en propietario de la tierra repartida, por la oposición de socialistas y radical-socialistas.

$4^{\text {a }}$ En el PLBRA se plasman, en frágil y contradictorio equilibrio, los principios e intereses en materia de reforma agraria, de una coalición gubernamental demasiado amplia y heterogénea, sobre todo en su sector republicano - de izquierda, moderados y conservadores-, a la hora de implantar la acción de gobierno (nacionalización de la tierra expropiada frente a generosa exención del propietario cultivador directo; régimen opcional entre la explotación colectiva o la individual; institucionalización centralizada de la reforma, desde un ámbito preferentemente extramunicipal - Juntas por partidos judiciales-, en contraste con la potenciación de juntas, asociaciones y sindicatos de cultivadores, a nivel local, etc.).

$5^{a}$ No se descarta la ocupación temporal («concesión en disfrute», recordemos), pero el objetivo principal del PLBRA ahora, es la expropiación de la tierra, nacionalizada por el Estado (aceptando la recurrente reivindicación de los socialistas), una vez subrogado en el dominio expropiado, en tanto que sólo cede a los campesinos beneficiarios el dominio útil, pero no el directo, que conserva como nuevo titular dominical. En consecuencia, las formas contractuales de cesión de la tierra que materialicen el asentamiento no permitirán la redención del canon, ni un posible acceso a la propiedad de las fincas objeto de reparto.

$6^{a}$ Aunque se mantienen los mismos límites de superficie máxima disponible para sus propietarios, en el PLBRA se pretende penalizar, en puridad, únicamente a los absentistas que ceden la tierra para su cultivo, en beneficio del dueño que la explota directamente, que queda eximido por completo de la ocupación y/o de la expropiación, salvo por causa de presión social.

$7^{\mathrm{a}}$ En el orden de prelación de las tierras afectadas y en el cálculo de las indemnizaciones, se constata la finalidad básicamente antiseñorial del ataque a la propiedad terrateniente, especialmente de la que se posee a título hereditario, que ocupa el primer lugar en el orden de preferencia.

$8^{\text {a }}$ Se establece una creciente y compleja casuística expropiatoria, en la que destacan tanto la inclusión del arrendamiento sistemático durante diez o más años, como, sobre todo, la expropiación por motivo de presión social, cuya máxima preferencia, alterando el orden de prelación de las tierras afectadas, puede llegar a ser declarada con el acuerdo previo de la Junta Central. Ambas causas expropiatorias van a perdurar en las propuestas normativas siguientes.

$9^{\text {a }}$ Finalmente, tanto el sistema indemnizatorio como la forma de pago de los derechos económicos reconocidos (cantidades en metálico hasta 500.000 pesetas), son muy gravosos para las finanzas públicas, a pesar de que se sigue 
manteniendo el gravamen fiscal especial sobre los excesos de renta catastral rústica en todo el territorio republicano.

\section{LOS DICTÁMENES DE 7 DE OCTUBRE Y DE 26 DE NOVIEMBRE DE 1931 DE LA COMISIÓN PARLAMENTARIA ESPECIAL DE REFORMA AGRARIA}

Una vez recibido por la presidencia del Congreso de los Diputados el PLBRA, la mesa de la Cámara lo remitió a la Comisión parlamentaria especial designada para conocer y dictaminar dicho proyecto ${ }^{64}$. Los vocales fueron elegidos de acuerdo con lo establecido por el $R P C C$, en proporción a los diferentes grupos parlamentarios presentes en las Cortes Constituyentes, por lo que la mayoría gubernamental contaba también en la Comisión con los apoyos necesarios para sacar adelante el Proyecto. Malefakis ha llamado la atención, al respecto, señalando que la presencia de independientes y de grupos parlamentarios minoritarios en las Cortes - de opinión más moderada o conservadora durante el primer bienio republicano-, impedía una representación proporcional más equilibrada en las comisiones en beneficio de los grupos mayoritarios, por lo que «la posición de la izquierda era normalmente más fuerte (...). De ahí el repetido fenómeno de unas comisiones que presentaban proyectos más radicales de lo que las Cortes podían aceptar». Esto no se corresponde con la realidad parlamentaria de una Cámara sobre la que algún autor ha podido afirmar (consciente de cierta exageración, no obstante) al menos para este momento de la coyuntura política, que era prácticamente toda ella Gobierno ${ }^{65}$.

\footnotetext{
64 En la misma sesión de 25 de agosto se había dado cumplida respuesta a la petición de AlcaláZamora, acordándose el nombramiento de una Comisión Parlamentaria Especial (CRA) -artículo 35.1 del Reglamento provisional de las Cortes Constituyentes [RPCC] (DSCC, núm. 3, de 18 de julio de 1931, apéndice 19)-, compuesta por 21 diputados, que serían elegidos, por aclamación, al día siguiente en la sesión del 26 de agosto. Sus integrantes eran: Juan Díaz del Moral (Agrupación al Servicio de la República: ASR), elegido presidente; Lucio Martínez Gil (Partido Socialista Obrero Español: PSOE), vicepresidente; José $M^{a}$ Álvarez Mendizábal (Partido Republicano Radical: PRR), secretario; Fernando Valera Aparicio (Partido Republicano Radical Socialista: PRRS), vicesecretario; y los vocales José Palanco Romero (Acción Republicana: AR); Diego Hidalgo Durán (PRR); Juan Calot Sanz (PRR); Eloy Vaquero Cantillo (PRR); Juan Morán Bayo (PSOE); Pedro García y García (PSOE); Juan Canales González (PSOE); Ramón Beade Méndez (PSOE); Ricardo Crespo Romero (Partido Republicano Federal: PRF); Antonio Pérez Torreblanca (PRRS); Benito Artigas Arpón (PRRS); Tomás Domínguez Arévalo (Tradicionalistas: TRA); Tomás Marcos Escribano (Partido Republicano Progresista: PRP); Manuel Serra Moret (Esquerra Republicana de Catalunya: ERC); Luis Companys Jover (ERC); José Martínez de Velasco (Minoría Agraria: AGR) y Bibiano Fernández-Osorio Tafall (Federación Republicana Gallega: FRG) (DSCC, núm. 27-28, de 26-27 de agosto de 1931, pp. 598 y 657, respectivamente). Igualmente, en el Acta de la primera sesión de la CRA, de 27 de agosto, consta la designación del Presidente (Díaz del Moral), del Vicepresidente (Martínez Gil), del Secretario (Álvarez Mendizábal), y del Vicesecretario (Valera Aparicio) de la CRA.

65 La cita del hispanista norteamericano y la referencia a que la Cámara era prácticamente en su totalidad gobierno en dicha coyuntura política, en MALEFAKIS, E.: Op. cit., p. 228, y en JULIÁ,
} 
Tampoco por lo que se refiere a la CRA, como tendremos ocasión de matizar, en donde las diversas minorías estaban representadas así: PSOE, 5 vocales; PRR, 4; PRRS, 3; ERC, 2; AR, 1; PRF, 1; TRA, 1; PRP, 1; ASR, 1; AGR, 1: y FRG, 1. Hay que tener en cuenta, en este sentido, que el art. 12 del RPCC imponía el criterio de proporcionalidad dentro de las comisiones al asignar el número de vocales correspondientes a los grupos o fracciones parlamentarios en «proporción a su fuerza numérica», y que el número mínimo de diputados de éstos era de diez, reconociéndose en el art. 11, apartado $4^{\circ}$., que podían formar grupo propio, a criterio de la Mesa presidencial, aquellos diputados no adscritos a una fracción parlamentaria concreta, en concepto de indefinidos o independientes.

Sin embargo, de la consulta de las Actas de las sesiones de la CRA ${ }^{66}$ celebradas tanto en los meses inmediatos de septiembre, octubre y noviembre de 1931, como durante la agotadora tramitación del PLBRA de marzo de 1932, se colige que en gran número de ocasiones surgieron disputas y discrepancias en el seno de las minorías gubernamentales (que disponían de una amplia mayoría en la Comisión, luego más reducida con la salida del PRR de la coalición gubernamental, en diciembre de 1931) e, incluso, entre vocales de una misma fracción parlamentaria, bien por cuestiones formales (régimen de discusión del proyecto, número de sesiones a celebrar, consultas a los grupos parlamentarios, etc.), bien por cuestiones de fondo (enmiendas, votos particulares, explicaciones de voto, etc.). Se sentaba así, un muy ilustrativo precedente parlamentario en la Comisión, de los incidentes de índole exclusivamente técnico-jurídica, en apariencia, pero también política, en realidad, que iban a multiplicarse posteriormente en el salón de plenos del Congreso de los Diputados con la discusión de dicho PLBRA de 1932.

Es justo lo que sucedería tras el acuerdo adoptado en la segunda sesión celebrada el 1 de septiembre sobre la propuesta del socialista Martínez Gil para que la Comisión se centrase exclusivamente en la discusión del PLBRA y en la emisión del correspondiente dictamen, en vez de entrar a debatir y analizar, simultáneamente, la ingente documentación especializada sobre la reforma agraria que se estaba recibiendo en el seno de la $\mathrm{CRA}^{67}$. En efecto, con el análisis concreto de las diversas bases del proyecto y de las modificaciones introducidas en el dictamen

Santos: «Sistema de partidos y problemas de consolidación de la democracia» en Política en la Segunda República. Ayer (Madrid) 20 (1995), p. 120, respectivamente.

66 Dichas Actas de sesiones (1931-1932), inéditas hasta el momento, se hallan depositadas en Archivo Cortes, Congreso de los Diputados, Serie General, Legajo 543, Exp.1. Todas las referencias subsiguientes a las actas sólo harán mención al día de celebración, para no repetir abusivamente el dato relativo a la localización de esta fuente primaria.

67 Ya se ha hecho referencia al gran número de informes y documentos de sociedades y corporaciones agrícolas que en ese momento estaban llegando torrencialmente, pero los vocales de la Comisión estudiaron entre otros: el anteproyecto de la CTA junto a los votos particulares a él formulados (se solicitó su remisión al Gobierno); el folleto Mi proyecto de reforma agraria, de Adolfo Vázquez Humasqué (recordemos, miembro de la CTA y, luego Director General de Reforma Agraria); o el libro La reforma agraria en España, del Vizconde de Eza (Luis Marichalar), de acuerdo con la información procedente del Acta de la $2^{\mathrm{a}}$ sesión, de 1 de septiembre de 1931.

Hispania, LXIV/1, núm. 216 (2004) 267-324 
surgirían, inmediatamente, fuertes discrepancias. Así mismo, y como se ha indicado, serían motivo de serios enfrentamientos, cuestiones tales como la mayor o menor urgencia en dictaminar, caso, por ejemplo, del vocal radical Vaquero Cantillo, cuando excitó a la Comisión «a dar fin cuanto antes a sus trabajos» (Acta de la sesión de 3 de septiembre); o cuando se polemizaba sobre el carácter reservado de los compromisos adoptados por los vocales, para pasar a declarar, de forma contradictoria, la absoluta reserva, primero; y la plena libertad para informar sobre los mismos, después, en dos sesiones consecutivas (Actas de los días 8 y 9 de septiembre, respectivamente). El vocal radical, y secretario de la CRA, Álvarez Mendizábal, por ejemplo, con el fin de abreviar todo lo posible la tramitación del PLBRA y adelantar el dictamen, hizo la siguiente propuesta: «Que para discutir cada Base solo se conceda la palabra al Vocal que hable en nombre de un grupo parlamentario y por tiempo máximo de diez minutos, procediéndose seguidamente a votar las enmiendas que se presenten por escrito, apoyándolas en cinco minutos de discurso; si no se aprueba este régimen, pide que conste en Acta el tiempo que cada orador consuma en sus intervenciones» (Propuesta a la que se opuso, por cierto, el socialista Martínez Gil, aunque sería finalmente aprobada pocos días después, en la sesión del 17 de septiembre). En la misma reunión, otro vocal radical, Diego Hidalgo, leía un escrito en el que mostraba su «disconformidad con la totalidad del proyecto» y anunciaba que consultaría con su minoría sobre la conducta a adoptar. Su correligionario Álvarez Mendizábal, se adheriría, así mismo, a su declaración ${ }^{68}$. Tengamos en cuenta, en este sentido, que, según la historiografía especializada (Malefakis, por ejemplo), la radicalización de los dictámenes habría sido fruto de las presiones de socialistas y republicanos de izquierda, pero en realidad el rechazo inicial más contundente del proyecto provino del partido radical, integrante aún de la coalición gubernamental, a pesar de que sus vocales lograron incorporar varias modificaciones de cierta entidad al primer Dictamen.

A finales del mes de septiembre, y tras haber consumido diecisiete reuniones de trabajo, el vocal progresista Marcos Escribano propondría, como solución de emergencia, que la CRA se constituyese en sesión permanente, "por los sucesos que repetidamente se producen en distintas provincias," en implícita referencia a los problemas de orden público y a la conflictividad rural vivida en Andalucía y Extremadura, especialmente. El presidente Díaz del Moral, recogió dicha propuesta al propugnar que desde el día siguiente, 1 de octubre de 1931, a las diez y media de la mañana, la Comisión quedase constituida en sesión permanente para dictaminar con urgencia el PLBRA, siendo aprobada de forma unánime con la puntualización del radical Álvarez Mendizábal, «de que, por no haberse observado las bases acordadas para la forma de discusión [en la sesión de 17 de septiembre], había dado lugar a que hubiera que adoptarse esta resolución ${ }^{69}$. Como resultado inmediato, la CRA presentaría su Dic-

68 Acta de la sesión de la CRA, de 9 de septiembre de 1931.

${ }^{69}$ Acta de la sesión $17^{\mathrm{a}}$, de 30 de septiembre de 1931. 
tamen sobre el PLBRA de 7 de octubre. En su preámbulo, tras mencionar el esfuerzo «agotador» y la ardua labor dedicados al análisis minucioso y al amplio debate de todas sus bases, se reconocía explícitamente que «la Comisión no ha logrado llegar al acuerdo unánime en casi ninguno de los temas discutidos», por lo que iba a ser objeto, por tanto, de la presentación de diversos votos particulares a la totalidad para su posterior debate en el pleno del Congreso.

El Dictamen presentaba varias modificaciones, en un sentido más radical, del PLBRA $^{70}$. En primer lugar, se aprobaba que el cupo anual de asentamientos campesinos determinado por el Gobierno, una vez transcurrido el primer año, tenía que ser superior al del año anterior, cuando el proyecto no establecía un cupo concreto para los asentamientos en años posteriores (recordemos, entre 60.000 y 75.000 familias campesinas sólo para el primer año). Esta adición al proyecto del dictamen fue propuesta, por cierto, por el vocal radical Álvarez Mendizábal, con el voto en contra del agrario Martínez de Velasco, no por ningún socialista ni republicano de izquierda ${ }^{71}$. La iniciativa había generado un interesante debate previo entre el socialista Martínez Gil y Álvarez Mendizábal, al defender el primero que los asentamientos en el primer año debían beneficiar a 75.000 familias (140 millones de coste para el Estado, unas 1.870 pesetas por familia en números redondos), pero como mínimo, ya que, sostuvo en la comisión, el cupo máximo debería llegar hasta un total de $150.000^{72}$. Para el diputado radical, por el contrario, dicho coste para el cupo máximo de 75.000 familias alcanzaría la enorme cifra de 2.500-3.000 millones de pesetas. El presidente, Diaz del Moral, por su parte, consideraba que un promedio de gasto por familia de unas 2.000 pesetas era «a todas luces insuficiente», y que «no sería conveniente dejar a otros Gobiernos la obligación de asentar un número de familias por año que les fuera imposible». En consecuencia, propuso que se fijara el cupo asentable anual para posteriores ejercicios, en función de las disponibilidades económicas para asentamientos consignadas en los presupuestos del Estado, dejando en libertad para fijar dicho cupo al Gobierno. Y así se aprobó, pero con la adición señalada ${ }^{73}$.

Respecto a los efectos territoriales de la ley, se introducía otra modificación de entidad, puesto que se afirmaba expresamente que afectarían a todo el territorio nacional ${ }^{74}$, con la salvedad de que su inmediata aplicación sólo se produciría en los mismos términos municipales de las provincias del proyecto (las de

${ }^{70}$ El Dictamen está publicado en DSCC, núm. 51, de 7 de octubre de 1931, Apéndice $2^{\circ}$.

71 Acta de la sesión $3^{\text {a }}$, de 2 de septiembre de 1931 .

72 La reivindicación de este cupo máximo concreto ya la habían hecho, como se dijo, los vocales socialistas en el seno de la CTA, siendo plasmada en concreto en el voto particular a la totalidad que presentaron a la ponencia de la anterior y que remitieron al Gobierno (FNTT: Memoria... Op. cit., p. 347).

${ }_{73} \mathrm{El}$ debate sobre el coste y los cupos mínimo y máximo de los asentamientos, en Actas de las sesiones $2^{\mathrm{a}}$ y $3^{\mathrm{a}}$, de los días 1 y 2 de septiembre.

${ }^{74} \mathrm{La}$ aplicación de los asentamientos en todo el territorio nacional fue una recurrente reivindicación de Martínez Gil, secretario general en este momento de la FNTT de la UGT (Acta de la sesión $3^{\mathrm{a}}$, de 2 de septiembre). 
Andalucía, Extremadura, Ciudad Real y Toledo), con la incorporación de las de Albacete y Salamanca; y - - sto es de gran trascendencia-, en «todos aquellos otros territorios en donde existan tierras de señorío y allí donde haya grave problema de paro campesino» (base $2^{a}$ ). A esta nueva redacción se llegó tras el encargo realizado a los vocales Martínez Gil (PSOE) y Serra Moret (ERC) para que, recogiendo lo debatido y aprobado en las sesiones de los días 2 y 3 de septiembre, presentaran un nuevo texto. Y en efecto, los párrafos $1^{\circ}$ y $2^{\circ}$ de la base $2^{\mathrm{a}}$, tal y como serían dictaminados, incorporarían las modificaciones señaladas, con la salvedad de que la inclusión de la provincia de Salamanca, en particular, se debió a la iniciativa concreta del vocal progresista Marcos Escribano (contaba, no obstante, con la simpatía de los socialistas). En consecuencia, las posibilidades de extensión territorial de la reforma se ampliaban considerablemente ${ }^{75}$.

En la base $5^{\text {a }}$, igualmente, se regulaba tanto las condiciones para una posible expropiación, u ocupación temporal, en su caso, como el recargo tributario sobre la propiedad rústica que excediera de los límites de superficie, según cultivos (y sobre la renta catastral de más de 10.000 pesetas) del Proyecto, pero con una mayor restricción sobre las tierras de secano dedicadas al cultivo arbóreo, puesto que el exceso de superficie afectada se computaba a partir de 100 hectáreas frente a las 200 de la CTA y del PLBRA, con lo que la cantidad de tierras disponibles para la reforma aumentaba notablemente en los cultivos arbóreos, asociados o no a otros cultivos. Este exceso computable superior a 100 ha fue aprobado a propuesta de Martínez Gil, con el voto en contra de los vocales radicales Calot Sanz, Vaquero Cantillo y Álvarez Mendizábal, y con el también contrario del presidente Díaz del Moral ${ }^{76}$.

Además, en la base $7^{a}$ relativa a las concesiones en disfrute u ocupaciones temporales para anticipar los asentamientos, se introducía una importante modificación al establecerse un canon en favor del propietario, titular de las tierras ocupadas, que sería fijado por el IRA, y que comenzaría a devengarse desde el momento de la ocupación. Esta adición sería resultado de una propuesta del vocal gallego Fernández-Osorio (FRG) —diputado de la mayoría gubernamental-, que sería aprobada por nueve votos contra seis (los cinco de los vocales socialistas más el de Marcos Escribano). Evidentemente, la mayoría republicano-socialista no sólo no votaba de modo unánime, sino ni siquiera como un bloque mayoritario de socialistas y republicanos de izquierda frente a sectores más conservadores y de republicanos de derecha, tal y como han afirmado algunos autores ${ }^{77}$.

\footnotetext{
75 La lectura de la redacción definitiva de dicha base, en Acta de la sesión $15^{\mathrm{a}}$, de 24 de septiembre. Los vocales socialistas de la CTA ya intentaron incluir las provincias de Albacete y Salamanca en la ponencia repetidamente mencionada, pero su petición fue rechazada. Por ello, fueron propuestas, de nuevo, en el voto particular referido con anterioridad.

${ }^{76}$ Acta de la sesión $8^{a}$, de 10 de septiembre. La base $5^{a}$ había sido dictaminada en la sesión celebrada el día anterior, de 9 de septiembre, a reserva de la votación de la enmienda de Martínez Gil.

71 Acta de la sesión $8^{\mathrm{a}}$, de 10 de septiembre.
} 
En cuanto a la base $12^{\mathrm{a}}$, relativa al orden de preferencia para los asentamientos, se originó un amplio y controvertido debate en la sesión de 16 de septiembre, en el que se llegó a acordar, por iniciativa de Martínez Gil, que se invitase a Alcalá-Zamora o a Fernando de los Ríos, para que acudieran a la Comisión con el fin de aclarar motivos sobre dicho orden. Igualmente, se aprobó en la sesión del día siguiente, la propuesta de un nuevo régimen de discusión de Álvarez Mendizábal, y se informó de la reunión mantenida por Díaz del Moral con AlcaláZamora, en la que el Presidente del Gobierno aceptó la invitación para acudir a la CRA cuando los vocales hubieran avanzado más con sus discusiones, asistiendo él mismo u otro miembro del Gobierno ${ }^{78}$. Ante el «impasse» producido, Martínez Gil defendió la necesidad de ir aprobando aquellas bases menos problemáticas, primero, y de repartir, después, las enmiendas escritas sobre las bases de mayor discusión entre los vocales para que, antes de su votación, pudieran ser conocidas en su literalidad. Dicha iniciativa permitió que fueran aprobadas las bases menos controvertidas y que se agilizara la discusión del PLBRA ${ }^{79}$.

Finalmente, se consiguió reanudar la discusión sobre la base $12^{\mathrm{a}}$, con el debate de varias enmiendas y votos particulares. El orden de preferencia para los asentamientos, regulado en dicha base, tanto para las concesiones como para las expropiaciones definitivas, «salvo modificaciones excepcionales de utilidad o urgencia», experimentaría también importantes cambios, ya que a las tierras de origen señorial transmitidas a título hereditario del Proyecto, se añadían las de igual origen, pero adquiridas a su vez por legado o donación; y las de buena calidad cercanas a los "núcleos urbanos, poblados o caserios o vías de comunicación» (propuestas por la CTA en su ponencia, pero suprimidas en el proyecto presentado por Alcalá-Zamora), estando afectadas en dicho grupo las incultas de buena calidad, las cultivadas deficientemente y las no explotadas directamente por el propietario; sin que se hiciera referencia alguna, al respecto, a las de explotación directa (que sí pođían ser objeto de ocupación, en último término, en la ponencia de la CTA $)^{80}$, de acuerdo con los criterios preponderantes de antiseñorialismo y antiabsentismo del PLBRA, de indudable simpatía entre los sectores republicanos de la coalición gubernamental. Dentro de la prelación de

\footnotetext{
78 Actas de las sesiones $10^{\mathrm{a}}$ y $11^{\mathrm{a}}$, de 16 y 17 de septiembre, respectivamente.

79 Acta de la sesión $12^{\mathrm{a}}$, de 18 de septiembre. No obstante, el número de vocales asistentes comenzaría a disminuir a partir de entonces, sin que pudieran efectuarse en algún momento las votaciones por no estar reunidos el número suficiente de vocales, como ocurrió en la sesión $13^{\mathrm{a}}$, de 22 de septiembre, con una enmienda de Marcos Escribano al párrafo $3^{\circ}$ de la base $19^{\mathrm{a}}$.

${ }^{80}$ Esta reintroducción del criterio de la ponencia de la CTA, con la salvedad matizada, se debió a la aprobación de una enmienda de Martínez Gil (Acta de la sesión $16^{\mathrm{a}}$, de 25 de septiembre). No obstante, como veremos más adelante, las tierras de explotación directa por sus propietarios no quedarían expresamente exceptuadas, como sí había hecho el PLBRA («a buen uso y costumbre», recordemos), salvo cuando fueran modelo de explotación técnica y económica, y a instancia de parte, por lo que cabe interpretar, a sensu contrario, que sí podían ser afectadas, implícitamente (véase base $24^{a}$ del proyecto dictaminado, de 7 de octubre de 1931).
} 
tierras se incluían también (si bien en último lugar), las arrendadas, pero desde doce o más años, y no desde diez como propugnaba el Proyecto, no considerándose como arriendo el concertado en forma de aparcería, cuando el propietario cooperaba equitativamente en el cultivo (esto se regulaba igual que en el proyecto), ni tampoco el del usufructuario (esto sí que era novedoso). Estos cambios, en particular, no suponían una mayor radicalización del dictamen, sino todo lo contrario. Así mismo, quedaban afectadas las tierras susceptibles de regadío, inmediatamente después de las de origen señorial, con idénticos condicionantes a los del PLBRA (obligación legal de riego por existir un embalse, existencia de obras hidráulicas financiadas por el Estado) ${ }^{81}$.

Las modificaciones de mayor entidad, en fin, se referían a la definición de las tierras señoriales, al pago o no de indemnizaciones, a la forma de abono y de capitalización, o a los efectos retroactivos de la ley. Por lo que se refiere al primer aspecto, la base $13^{\mathrm{a}}$ prescribía que: «Se considerarán tierras de señorío aquellas fincas rústicas que hubieran llevado anejo el señorío jurisdiccional abolido por decreto dado por las Cortes en 6 de Agosto de 1811, y cuyos propietarios lo sean por herencia, legado o donación». En relación con las tierras de este origen, Francisco Tomás y Valiente ha destacado las extraordinarias consecuencias jurídicas de la abolición del régimen señorial por dicho decreto de 1811: supresión de las jurisdicciones señoriales; abolición de diversos monopolios, privilegios y prestaciones a ellas anejos; y conversión del señorío territorial y solariego en propiedad particular, afirmando expresamente que el mismo: "consolidó, pues, los derechos reales sobre la tierra de los señores, convirtiéndolos de titulares de un dominio eminente, en titulares de un derecho pleno de propiedad ${ }^{82}$.

Para estas tierras, por consiguiente, no había derecho alguno a indemnización salvo las mejoras que el propietario hubiera introducido en el fundo por sí mismo. La indemnización, sólo por dichas mejoras, fue aprobada por 9 votos contra 6, con el voto favorable de: los socialistas Martínez Gil, Beade, Canales, García y García, y Morán; de los radical-socialistas Artigas y Pérez Torreblanca; y de los republicanos de izquierda Palanco (AR) y Serra Moret (ERC); y con el voto contrario de: los radicales Hidalgo, Vaquero y Álvarez Mendizábal; el independiente Díaz del Moral (ASR); el progresista Marcos Escribano; y el agrario Martínez de Velasco ${ }^{83}$. La definición literal sobre qué se entendía por tierras de señorío fue iniciativa del vocal de ERC Serra Moret, cuya enmienda a

${ }^{81}$ Tras las tierras de regadío, seguían en el orden de prelación las mencionadas de buena calidad próximas a las zonas especificadas, las que se habían adjudicado a la Hacienda Pública, y las de la Iglesia, Comunidades religiosas y otras personas jurídicas de interés público. Como se ha dicho, las arrendadas serían las últimas en la preferencia. No obstante, también el dictamen prescribía la causa expropiatoria por motivo de presión social, con carácter absolutamente prioritario tal y como hacía el PLBRA.

82 TOMÁs y VAlıENTE, Francisco: El marco político de la desamortización en España, Barcelona, $1983,4^{a}$ ed., p. 155.

83 Acta de la sesión $17^{\mathrm{a}}$, de 30 de sepriembre.

Hispania, LXIV/1, núm. 216 (2004) 267-324 
la base $13^{\mathrm{a}}$ fue aprobada con el voto en contra de Díaz del Moral y la abstención de Marcos Escribano y Vaquero Cantillo84. Según Mariano Azpeitia, abogado especialista en la materia y luego diputado de la minoría popular agraria en la legislatura ordinaria (1933-1935), este dictamen «estableció un sistema de indemnizaciones que, de prevalecer, hubiera constituído un verdadero despojo, una verdadera confiscación de la propiedad, porque en determinados casos nada pretendía indemnizar, y, en otros, la indemnización se esfumaba en forma tal, que equivalía a la nada o poco menos» ${ }^{85}$.

Para el propietario expropiado con derecho a indemnización, el Dictamen establecía el pago de una renta en títulos nominativos, de carácter transferible, pero sólo mediante legado o herencia, que estaba gravada, a su vez, por un impuesto progresivo con un tipo variable del 10 al 60 por 100 , sustitutivo de la contribución rústica (base $14^{\mathrm{a}}$ ). En cuanto a la capitalización de la renta, la valoración iba en función del tipo de porcentaje aplicado sobre el importe de la misma:

\section{CUADRO 2}

CAPITALIZACIÓN DE LA RENTA DE LAS TIERRAS EXPROPIADAS SEGÚN EL DICTAMEN DEL PLBRA DE 7 DE OCTUBRE DE 1931

\begin{tabular}{|c|c|}
\hline UMBRALES DE RENTA EN PESETAS & TIPO DE CAPITALIZACIÓN \\
\hline inferior a 20.000 & $6 \%$ \\
\hline superior a 20.000 y menor de 30.000 & $7 \%$ \\
\hline " " 30.000 “ " " 50.000 & $8 \%$ \\
\hline " " $50.000 "$ " " 100.000 & $9 \%$ \\
\hline " “ $100.000 "$ " “ 200.000 & $10 \%$ \\
\hline “ “ 200.000 & $12 \%$ \\
\hline
\end{tabular}

FUENTE: Elaboración propia, según la Base $14^{a}$ del Dictamen del PLBRA

${ }^{84}$ Acta de la sesión $18^{a}$, de 1 de octubre.

85 AZPeitia, Mateo: La reforma agraria en España, Madrid, 1932, p. 100. Coincide con la opinión de este destacado conservador Malefakis, para quien, con la inclusión de esta cláusula, "por primera vez en la historia española moderna, se admitía en un proyecto de reforma agratia la pena de incautación de la propiedad». Sin embargo, para Peter Dorner, de las diversas formas de adquisición de tierras para su redistribución en políticas de reforma agraria, la confiscación de la propiedad terrateniente por el Estado, sin compensación económica alguna para sus dueños, ha sido una de las más empleadas «en la mayor parte de los países en que se han llevado a cabo reformas fundamentales». Y es que si se quiere, en definitiva, conseguir una mejor distribución de la riqueza rústica, «la reforma agraria siempre debe tener, en parte, un carácter de confiscación». Las citas de estos dos autores, en MALEFAKIS, E.: Op. cit., p. 220, y DORNER, Peter: Reforma agraria y desarrollo económico, Madrid, 1974, pp. 55-58, respectivamente. 
Todas estos requisitos sobre indemnización, forma de pago y capitalización de la renta junto con sus tipos, fueron propuestos por Martínez Gil, en una enmienda que vino a sustituir en su totalidad a la base $14^{\text {a }}$ del PLBRA, con el voto en contra de Díaz del Moral, Marcos Escribano, el federal Crespo Romero y, de nuevo, los radicales Hidalgo y Vaquero. Uno de los aspectos más criticables, por cierto, de este Dictamen, para el especialista agrario de la revista Economía Española, Fernando Campuzano y Horma, junto al mayor número de fincas expropiables que implicaba, era precisamente la aplicación de unos tipos de capitalización muy elevados, porque dejaban, en su opinión, «exiguas» las indemnizaciones ${ }^{86}$.

Respecto a la retroactividad de la ley, se reconocía por primera vez a las partes afectadas, independientemente de los efectos civiles de carácter personal surgidos entre ellas, la posibilidad de impugnarla mediante la interposición de un recurso ante la Junta Central de Reforma Agraria, que resolvería, sin apelación, si procedía o no la aplicación retroactiva de la ley a la situación jurídica particular (base $15^{\mathrm{a}}$ ). Estas modificaciones sobre el alcance de los efectos de la retroactividad y la posible interposición del recurso ante la Junta Central se debieron a la aprobación de una enmienda del radical Diego Hidalgo, con el voto en contra de los cinco vocales socialistas y de Marcos Escribano ${ }^{87}$.

El régimen de excepciones de la base $24^{\mathrm{a}}$, finalmente, sí era más radical que el del proyecto, puesto que sólo eran exceptuadas de la ocupación temporal, en su caso, o de la expropiación definitiva - no del gravamen especial de la base $6^{a}$-, las tierras asignadas a la explotación forestal y las dedicadas a pastos que no eran susceptibles de cultivo permanente; además de las explotaciones ejemplares que sirvieran de modelo técnico y económico, de acuerdo con la resolución del IRA, y siempre a instancia de parte. El dictamen, en este sentido, no exceptuaba expresamente, a diferencia del PLBRA (en lo que era una modificación de relevancia, siguiendo el explícito criterio antilatifundista de la CTA, con el indudable apoyo de los socialistas), ni los bienes rústicos explotados directamente por sus dueños "a buen uso y costumbre", ni los que contribuyeran al mantenimiento de una industria rural o agropecuaria. Por lo que se refiere a dichos bienes rústicos de explotación directa, Malefakis ha matizado (contradiciéndose a sí mismo respecto a lo afirmado anteriormente sobre el peso de los vocales extragubernamentales en la CRA) que, aunque estas tierras no quedaron exentas, «los moderados conservaron el suficiente poder en el seno de la Comisión para evitar que (...) se inscribieran en un lugar preferente en el orden de expropiación ${ }^{88}$. Curiosamente, en la muy radical, para este historiador, ponencia de la CTA, por el gran ataque que suponía, entre otros aspectos, para

\footnotetext{
86 La aprobación de la enmienda de Martínez Gil, en Acta de la sesión 18a , de 1 de octubre (la última que se celebró antes de la presentación del Dictamen), y la cita del especialista agrario, en CAMPUZANO y HORMa, F.: Op. cit., p. 49.

${ }^{87}$ Acta de la sesión $18^{\mathrm{a}}$, de 1 de octubre.

88 MalefaKis, E.: Op. cit., pp. 219-220.
}

Hispania, LXIV/1, núm. 216 (2004) 267-324 
los grandes propietarios terratenientes, las tierras cultivadas directamente por sus dueños sí que quedaban afectadas (para la ocupación temporal a corto plazo, recordemos), pero en el último lugar del orden de preferencia establecido en dicha ponencia. En el dictamen, por contra, no se trataba de que no estuvieran incluidas en un lugar preferente, sino de que no lo estaban expresamente (tal y como se matizó), lo cual no obviaba una posible afectación, en la medida en que no estaban explícitamente exceptuadas como en el PLBRA (como también se destacó) ${ }^{89}$.

Por último, el Dictamen también declaraba implícitamente la nacionalización del suelo al prescribir que el Estado se reservaba el dominio directo de las fincas expropiadas frente al dominio útil de los adjudicatarios, que se obligaban ante aquél al pago de un canon, con carácter irredimible, equivalente al $4 \%$ (el $4,5 \%$ en el proyecto de ley) de la indemnización satisfecha por el Estado al propietario expropiado (base $21^{\mathrm{a}}$ ). La aprobación de la reducción del canon abonable al Estado en medio punto fue a propuesta del vocal agrario Martínez de Velasco ${ }^{90}$. La nacionalización del suelo era consecuencia de la nueva titularidad del Estado en los derechos dominicales del propietario expropiado, de acuerdo con la nueva redacción dada a la base $14^{\mathrm{a}}$ en la enmienda de Martínez Gil, como se dijo anteriormente.

Una valoración final del primer Dictamen destacaría entre las novedades aportadas: la ampliación, con el apoyo socialista; del número de provincias en donde la ley sería aplicada de inmediato (Albacete y Salamanca), y la posibilidad de implantar el programa preferente de asentamientos en los términos municipales de otras provincias, allí donde existieran tierras de señorío y donde hubiera grave paro campesino; la reducción en 100 hectáreas de la superficie máxima disponible para sus propietarios en las tierras de secano dedicadas al cultivo arbóreo (que afectaba sobre todo al olivo); la indemnización exclusiva de las mejoras útiles incorporadas por el propietario en las tierras de origen señorial transmitidas a título lucrativo, junto a las de título hereditario; o la incorporación como tercer grupo de beneficiarios al censo de campesinos asentables, de los pequeños arrendatarios o aparceros que dispusieran de 10 hectáreas de secano como máximo. Sin embargo, las mayores aportaciones se centraban en el tipo de tierras afectadas, puesto que se acentuaba la impronta antiseñorial del PLBRA de agosto, además de por la confiscación de las tierras que ya conocemos, porque se incluían, igualmente, las tierras de origen señorial transmitidas a título lucrativo, es decir, no sólo por herencia, sino también

89 No obstante, pudo tratarse de una errata o de un error de omisión al transcribirse el contenido tanto de la base $12^{\mathrm{a}}$ (tierras afectadas) como de la $24^{\mathrm{a}}$ (excepciones) -tengamos en cuenta la similitud e idéntica literalidad de muchas de las bases del dictamen de la CRA con las del PLBRA-, si bien el análisis de la enmienda citada de Martínez Gil, aprobada en la sesión $16^{a}$ de la CRA, de 25 de septiembre de 1931, viene a reforzar la tesis expuesta, sobre que las tierras explotadas directamente por sus dueños no fueron expresamente incluidas, pero tampoco fueron exceptuadas, de igual forma, en el dictamen.

${ }^{90}$ Acta de la sesión $14^{\mathrm{a}}$, de 23 de septiembre. 
por legado o donación. Así mismo, y como ya se ha señalado, quedaba eximido por completo el cultivador directo de la tierra cuando la explotación era rentable y eficiente como modelo ejemplar de tipo técnico y económico (no, cuando su explotación era deficiente, o cabía interpretar que no alcanzaba estos criterios de rentabilidad y buena gestión), con lo que se consagraba el carácter claramente antirrentista y antiabsentista del Dictamen.

El Dictamen, en fin, si bien implicaba una mayor radicalización del PLBRA gubernamental, no era como consecuencia de la presión ejercida por una supuesta mayoría homogénea de izquierda, formada por socialistas y republicanos de esta tendencia, votando disciplinadamente en el seno de la CRA — como obedeciendo a consignas o programas previos, frente a otro bloque conservador (sobre todo cuando no habían abandonado todavía el gabinete, Alcalá-Zamora y Miguel Maura, y los radicales permanecerían en la coalición gubernamental hasta la formación del primer gobierno constitucional, a mediados de diciembre de 1931) - , sino como resultado de las negociaciones, discrepancias y, a veces, intereses contrapuestos entre los miembros de la mayoría gubernamental (muy heterogénea entonces), de acuerdo con el análisis de las votaciones de las actas. Hay que recordar, en este sentido, cómo se aprobaron diversas propuestas de entidad de los vocales radicales (cupo mínimo de asentamientos para el segundo año y los siguientes, que tanto comprometía el ritmo previsible de los mismos y su coste económico; o la facultad para interponer recurso contra la aplicación de la retroactividad ante la Junta Central del IRA), los cuales habían manifestado, de entrada, su rechazo al PLBRA y presentado un voto particular a la totalidad del proyecto dictaminado (Diego Hidalgo); o cómo también se incorporaron enmiendas relevantes de otros vocales de tendencia moderada o conservadora, como el del PRP Marcos Escribano (iniciativa para la inclusión de Salamanca entre las provincias en las que se aplicaría de inmediato el programa de asentamientos) o el agrario Martínez de Velasco (reducción del canon irredimible, abonable por el asentado, del $4,5 \%$ al 4\%). Así mismo, también se introdujeron modificaciones de republicanos de izquierda como el gallego Bibiano Fernández-Osorio (reconocimiento de un canon para el propietario en los supuestos de ocupación temporal) con el voto contrario, por ejemplo, de los vocales socialistas. En todo caso, la radicalización del dictamen era indudable y prueba evidente de cómo estaba repercutiendo en el seno de la CRA la intensidad creciente de las discrepancias políticas en el Gobierno y entre los partidos de la mayoría (socialista y radical, sobre todo, pero también de éste último con el radical-socialista; o con los republicanos moderados de la ex Democracia Republicana Liberal: DLR), acerca del proyecto de Constitución (en particular, sobre el derecho de propiedad y su posible socialización según el artículo 42) que por entonces estaba siendo objeto de disputado debate en el pleno de las Cortes ${ }^{91}$. Además, hay que tener en cuenta la controversia, dentro de la

91 Precisamente, en la sesión plenaria del día 7 de octubre se aprobaría la redacción final del artículo 42 (44 del dictamen definitivo) sobre el derecho de propiedad y su posible expropiación, sin 
misma discusión constitucional, sobre la "cuestión religiosa» (separación entre el Estado y la Iglesia) que, como factor político agravante, conduciría a una seria crisis de gobierno el 14 de octubre de 1931, materializada en el abandono (ahora sí, definitivo) de la presidencia por parte de Alcalá-Zamora, acompañado del Ministro de Gobernación, Miguel Maura. Ambos elegidos diputados en junio por la DLR, pero ya divididos, por el abandono de Maura y sus seguidores en el mes de agosto, en lo que serían dos partidos independientes: el PRP, de Alcalá-Zamora, fundado en dicho mes; y el Republicano Conservador (PRC), de Maura, poco después, en enero de $1932^{92}$.

Sobre esta crisis política, que supuso la primera ruptura de la coalición gubernamental formada por los partidos adheridos al Pacto de San Sebastián (agosto de 1930), y la incidencia que en ella tuvo la publicación del PLBRA dictaminado por la CRA, de 7 de octubre, se han manifestado diversos historiadores. Así, en opinión de Mercedes Cabrera, no sólo la llamada «cuestión religiosa» repercutió en dicha crisis, sino también las hondas modificaciones en un sentido más radical que el proyecto de reforma agraria patrocinado por AlcaláZamora había tenido en la Comisión, por las «presiones de socialistas y republicanos de izquierda» (esta autora, que parece seguir la tesis de Malefakis, obvia, al igual que éste, la rotunda oposición de los radicales al PLBRA, antes y después de ser dictaminado, tal y como hemos enfatizado). También de acuerdo con esta interpretación, pero más atinado en sus apreciaciones, Manuel Tuñón de Lara, para quien: «La perspectiva que da el tiempo concede solidez a la hipótesis de que el rechazo de su proyecto de reforma agraria fue una causa, por lo menos tan importante como la cuestión religiosa, para que Alcalá Zamora renunciase a seguir presidiendo el Gobierno provisional [sic]«. Por su parte, Edward Malefakis, conforme con que «la cuestión de la propiedad - que muchos autores han ignorado- fue también fundamental» para la dimisión del Presidente de Gobierno, ha insistido, pensamos que erróneamente, en que las «revisiones de la Comisión vinieron a significar un rechazo total de la propuesta de Alcalá-Zamora», entre otras razones porque dentro de la CRA, los «republicanos de izquierdas y los socialistas ocupaban 12 de los 21 puestos» ${ }^{93}$. En realidad, en nuestra opinión, no

indemnización, mediante ley especial aprobada por mayoría absoluta (DSCC, núm. 51, de 7 de octubre de 1931, p. 1.492). En el transcurso del debate de este artículo, ya se había generado una seria crisis política dentro de la mayoría gubernamental con el anuncio de la dimisión (luego retirada, tras los buenos oficios de Indalecio Prieto y la mediación del propio Besteiro) de. Alcalá-Zamora de la Presidencia del Gobierno.

92 La información relativa a la desaparición de la DLR y a su sustitución por dos nuevos partidos, en Varela Díaz, S.: Partidos y Parlamento en la Segunda República, Madrid, 1978, p. 76.

${ }^{93}$ Las citas de los tres historiadores en CABrera, M.: Op. cit., p. 177; Tuñón DE LARA, M.: Op. cit., p. 50, y MALEFAKIS, E.: Op. cit., pp. 220-221. Por lo que se refiere a la referencia de este último historiador sobre la composición partidaria de la CRA, hay que señalar que más bien eran catorce (trece como mínimo), los vocales que eran simpatizantes o integrantes de la mayoría gubernamental (en la que todavía formaban parte, se insiste, los radicales): cinco socialistas, tres radicalsocialistas, dos catalanistas de ERC, un republicano de FRG, un republicano de AR, un federalista y

Hispania, LXIV/1, núm. 216 (2004) 267-324 
cabe hablar de rechazo (y menos aún con carácter absoluto), como consecuencia de la rotunda oposición ejercida por una compacta mayoría de izquierda en el seno de la CRA, entre otras razones, porque:

$1^{\circ} \mathrm{Si}$ bien las modificaciones introducidas en el dictamen radicalizaron ciertos aspectos de entidad del PLBRA, la mayor parte del mismo permaneció inalterado ( $\mathrm{y}$ no sólo en cuestiones de tipo institucional o procedimental), como por ejemplo, sin ánimo de ser exhaustivo, en lo relativo a: los límites de superficie no afectada, a libre disposición de sus propietarios, prácticamente con los mismos topes y para idénticos cultivos; el mantenimiento del gravamen especial sobre excesos de renta rústica; la continuidad de la mayoría de los supuestos expropiatorios (presión social, tierras de origen señorial, las de regadío, las de la Iglesia y comunidades religiosas, las de arrendamiento sistemático, con la modificación introducida, sin duda menos radical, de computar el arriendo a partir de 12 años en vez de 10, como hacía el PLBRA), o la permanencia de la implícita nacionalización de la tierra afectada. No parece, ciertamente, que la continuidad de todos estos aspectos fundamentales permita considerar que las modificaciones incorporadas por el Dictamen viniesen a significar un «rechazo total» del proyecto de ley presentado por Alcalá-Zamora.

$2^{\circ}$ Esta visión interpretativa de parte de la historiografía especializada, además de minusvalorar las evidentes líneas de continuidad entre proyecto y dictamen, olvidan la muy relevante participación en la redacción del PLBRA (no sólo de su preámbulo) del socialista Fernando de los Ríos (en realidad, el más entendido en la materia entre los cuadros dirigentes del PSOE), y que, si bien Alcalá-Zamora tuvo un considerable protagonismo en la elaboración y, sobre todo, en la presentación ante las Cortes de dicho proyecto de ley, el mismo contó con el acuerdo y la aprobación del Consejo de Ministros, por lo que las enmiendas y modificaciones que se introdujeron, posteriormente, por ese supuesto bloque homogéneo de izquierda republicano-socialista en la CRA, no podían ir, de forma tan contundente (como se ha sostenido) contra lo aprobado por los principales dirigentes de los partidos de dicha tendencia, representados en el Gobierno.

$3^{\circ}$ De ahí que consideremos acertados los matices y valoraciones hechos por parte de la historiografía sobre la posible mayor influencia de los cambios experimentados por el PLBRA dictaminado en la dimisión de Alcalá-Zamora, si ponderamos el sentido heterogéneo de los diversos correctivos introducidos (radicales y no tan radicales), y, sobre todo, la incidencia, casi simultánea (no lo

un miembro de ASR, Juan Díaz del Moral, a quien no podemos considerar, propiamente, como conservador o de derechas (tampoco gubernamental, aunque coincidió a veces con los criterios de la mayoría dentro de la Comisión), de acuerdo con la actitud demostrada como presidente de la CRA y como diputado constituyente, y la índole de sus propuestas y votos particulares a los diversos PLBRA y dictámenes de la Comisión.

Hispania, LXIV/1, núm. 216 (2004) 267-324 
olvidemos), de la conflictiva discusión constitucional sobre el derecho de propiedad, que fue anterior a la de la cuestión religiosa.

$4^{\circ}$ Tampoco se hà valorado adecuadamente (por no haberse estudiado las Actas de las sesiones celebradas por la CRA) la actitud adoptada dentro de ella por los vocales del PRR, partido gubernamental todavía, hasta la aprobación de la Constitución el 9 de diciembre de 1931, ya que fue, quizá, el grupo más contrario al PLBRA en su conjunto, si bien por variadas razones tanto de tipo técnico-jurídico como de tipo político (rechazo a la nacionalización de la tierra afectada, oposición a la introducción de matices socializantes y colectivistas, defensa del acceso a la propiedad mediante censos redimibles, etc.), hasta el punto de que uno de sus vocales en la Comisión, Diego Hidalgo, presentó uno de los dos votos particulares a la totalidad que se interpusieron al mismo (el otro era de Juan Díaz del Moral), y que constituían, para todos los efectos, auténticos "proyectos» alternativos. A ninguno de estos dos vocales, por cierto, podemos adscribirlos, cabalmente, dentro de la tendencia de republicanos de izquierda que, junto a los socialistas, se opusieron, al decir reiterado de Malefakis, tan absolutamente al PLBRA.

$5^{\circ}$ Finalmente, sólo resta señalar que tampoco cabe sostener la repetida tesis sobre la autoría y el alcance de los cambios experimentados por el Dictamen de la CRA, si tenemos en cuenta que el mismo sería sustituido por un segundo Dictamen, tan sólo mes y medio después, por la propia Comisión en la que seguían siendo mayoritarios los mismos vocales de izquierda que, al parecer, habían rechazado tan rotundamente el de agosto precedente, con el fin exclusivo de acercar posiciones con los radicalés, miembros todavía de la coalición gubernamental, tras la salida de Alcalá-Zamora y Maura. En conclusión, el verdadero rechazo tanto del PLBRA de agosto como del primer dictamen de 7 de octubre de 1931, no provino de los sectores socialista y de republicanos de izquierda de la CRA, a pesar de las relevantes modificaciones que consiguieron incorporar al proyecto dictaminado, sino de los vocales del PRR y de algunos de los vocales más moderados, como el propio Presidente, Díaz del Moral, con cuyos votos particulares se estaban haciendo eco tanto de las protestas de las patronales agrarias, como de los sectores de la prensa más opuestos al tipo de reforma "socializante» que venía configurándose con el PLBRA, más acentuada todavía, desde su perspectiva, con el Dictamen de la CRA. Por ello, el segundo dictamen de 26 de noviembre, no sólo no podía tender más aún a la izquierda, sino que, por el contrario, si se quería acercar posiciones con los radicales, debería de experimentar un cierto giro moderado, en el sentido de una mayor restricción de todos aquellos aspectos de sesgo socialista, en beneficio del pequeño y, sobre todo, mediano propietario terrateniente.

Tras la resolución de la crisis con la formación de un nuevo gobierno republicano-socialista (15 de octubre de 1931), presidido ahora por Manuel Azaña, el dictamen de 7 de octubre, no llegaría a ser debatido en el pleno de las Cortes Constituyentes, porque, como se ha apuntado, fue objeto de rechazo por la propia 
Comisión parlamentaria, que emitió un nuevo Dictamen, de fecha 26 de noviembre de 1931, pocos días antes de que fuese aprobada la Constitución republicana ${ }^{94}$.

Como ya se dijo, el primer Dictamen fue objeto de la presentación de varios votos particulares a la totalidad por parte de los vocales Díaz del Moral y Diego Hidalgo (a los que se hará una sucinta referencia) ${ }^{95}$. El del presidente de la CRA propugnaba, por ejemplo, la reducción del alcance del principio de la retroactividad, aplicándolo sólo desde la fecha de constitución de la CTA, es decir, el 21 de mayo, y facultando a los particulares afectados por la aplicación de dicho principio, para recurrir, no a la Junta Central, sino al Tribunal Supremo de Justicia, con lo que se judicializaba el procedimiento ya en su primera base, en lo que suponía una mayor garantía procesal y sustantiva de los derechos de los propietarios afectados. Así mismo, defendía la creación de una serie de Comités en sustitución de las Juntas provinciales y locales, y la constitución de una Comisión Permanente dentro del IRA, presidida por un ministro a designar por el Gobierno. Respecto a los bienes rústicos «sometidos a las ordenaciones de esta ley", distintos de los propuestos en el Dictamen, Díaz del Moral incluía entre otros: los particulares del rey Alfonso XIII y los integrantes del patrimonio de la Corona, salvo cumplimiento de fines sociales o servicios

\footnotetext{
94 En la documentación relativa a las actas que se conservan en el Archivo del Congreso de los Diputados de las sesiones de la CRA, la última sesión numerada es la $18^{\mathrm{a}}$, de 1 de óctubre de 1931, las dos siguientes son ya de 25 y 27 de noviembre (la fecha del $2^{\circ}$ Dictamen es de 26 de noviembre), y la inmediata posterior es la de 30 de marzo de 1932, en la que ya se discutía entonces el nuevo PLBRA de Marcelino Domingo. Cabe interpretar, en consecuencia, que apenas debieron reunirse los vocales de la Comisión, teniendo en cuenta que ninguno de los dos dictámenes llegaron a ser debatidos en el pleno de las Cortes por los avatares de la coyuntura política (aprobación de la Constitución, salida de los radicales de la coalición gubernamental, formación del primer Gobierno constitucional republicanosocialista de Azaña, ya sin ellos, y rechazo ministerial del $2^{\circ}$ Dictamen de la Comisión).

${ }_{95}$ Estos votos particulares están publicados en los Apéndices $3^{\circ}, 4^{\circ}$ y $5^{\circ}$ respectivamente, del DSCC, núm. 51, 7 de octubre de 1931, destacando especialmente el del diputado radical Diego Hidalgo, no sólo pọr su extensión (22 capítulos, 131 artículos, 8 Disposiciones Transitorias, 9 Disposiciones Adicionales y 1 Disposición Final), sino por la brillantez jurídica del texto y la buena sistematización de las propuestas, frente a los diversos proyectos analizados hasta el momento. Por ello, en las Conclusiones aprobadas por la Asamblea Extraordinaria de los Peritos Agrícolas Españoles, celebrada en Madrid los días 23, 24 y 25 de octubre corriente en orden a la reforma agraria que se proyecta reali$z a r$, se llegó a afirmar que el voto particular «del Sr. Hidalgo Durán, se ocupa, dándole el rango que por su importancia merece, del aspecto técnico agrícola del problema; con tal acierto, a nuestro modo de ver, que la Asamblea (...) le ha considerado digno de hacerlo suyo con ligeras enmiendas y adiciones, que en nada sustancial modifican su meditada orientación agronomicas (Archivo Cortes, Congreso de los Diputados, Serie General, Legajo 544, Exp. 1, Doc. N $\left.^{\circ} 74\right)$. En este sentido, Ruiz Manjón ha destacado la gran incidencia de las ideas del diputado radical por Badajoz en las posiciones del partido, y cómo «el mismo Lerroux, en sus actos de propaganda de la segunda mitad de 1931, insistió siempre en la necesidad de calmar las inquietudes provocadas por anuncios de medidas radicales en la aplicación de la reforma. La postura tuvo, lógicamente, buena acogida entre las clases poseedoras y sirvió para sumar adhesiones al radicalismo» (RUIZ MANJóN, Octavio: El partido Republicano Radical, 1908-1936, Madrid, 1976, p. 307).
}

Hispania, LXIV/1, núm. 216 (2004) 267-324 
públicos; los adjudicados al Estado por deuda, herencia o legado, y los que poseyera con «el carácter de propiedad privada»; los de la Iglesia y los del clero secular y regular, de acuerdo con la normativa que estuviera vigente una vez aprobada la propia Constitución; o las fincas adquiridas de forma especulativa o para vivir de modo absentista ${ }^{96}$. El conjunto de bienes afectados, salvo los citados de la Corona, el monarca o el Estado, pasaban a ser inventariados por el IRA, siendo valorados posteriormente de acuerdo con la Ley de Expropiación Forzosa «que esté a la sazón vigente». Un aspecto crucial de este voto particular era que el propietario transmitía obligatoriamente sus tierras a pleno dominio, pero a censo reservativo, al Estado o al adjudicatario que hubiera designado el IRA, a cambio de un canon equivalente al $4 \%$ del valor líquido asignado al inmueble; estando capacitado el censatario para redimir el censo y, por tanto, acceder a la propiedad de la tierra.

El voto particular del radical Diego Hidalgo pretendía corregir el grave defecto del Dictamen que, para este diputado, radicaba, en definitiva, en "dar soluciones únicas a problemas múltiples». Dentro de los bienes sujetos a expropiación incluía, al igual que Díaz del Moral, los del patrimonio de la Corona y de propiedad particular «del último rey»; las de la Iglesia y asociaciones religiosas, y con la misma matización hecha por el presidente de la CRA en cuanto a la remisión tanto a la normativa especial como a la Constitución que estuvieran en vigor; los adquiridos con fines especulativos; etc. Lo más destacable de sus propuestas era que, después de la tasación de las fincas expropiadas, la transmisión se efectuaba también «en pleno dominio y bajo censo reservativo, al Instituto Agrario", o a los adjudicatarios designados por éste, pudiendo redimir dicho censo con la aprobación previa del Gobierno, tras oir a la Junta Central del Instituto Agrario. Para la redención del censo reservativo, el Gobierno procedía al pago del capital mediante títulos de Deuda Pública del Estado con un interés del 4\%, por un valor equivalente al $50 \%$ del mismo, cuando las fincas se hubieran tasado en menos de 500.000 pesetas; llegando hasta el $90 \%$ cuando lo hubieran sido en 1.000 .000 de pesetas o en cantidad superior (artículo 15). Según Malefakis, tanto el voto particular de Diego Hidalgo como el de Juan Díaz del Moral, recibieron fuerte apoyo en los círculos católicos y entre los terratenientes debido a su moderación, hasta el punto de que la Unión Económica, la patronal que iba a convertirse en el grupo de presión más poderoso del país, publicó los dos proyectos de ley propuestos en sus votos particulares, en el folleto Ante la reforma agraria (Madrid, 1932), para que se repartiera por toda España ${ }^{97}$.

El primer dictamen de la CRA, como ya se apuntó, no llegó a ser debatido en el Pleno del Congreso de los Diputados, porque tras la formación del primer Go-

96 La causa expropiatoria por razón especulativa y/o absentista sería incluida finalmente en la LBRA de 15 de septiembre de 1932 (Base $5^{\text {a }}$, apartado $5^{\circ}$ ), por iniciativa tanto de este diputado como del radical Diego Hidalgo.

${ }_{97}$ Malefakis, E.: Op. cit., pp. 224-225. 
bierno republicano-socialista presidido por Manuel Azaña, se intensificaron las disputas y desencuentros entre radicales y socialistas. Además, éstos últimos eran partidarios de discutir simultáneamente en las Cortes tanto el proyecto de reforma agraria como el constitucional, en contra del criterio de Azaña, favorable a posponer el primero en beneficio de la aprobación preferente de la Constitución (exigida además por el artículo 39 del $R P C C)^{98}$. En consecuencia, se llegó a un acuerdo según el cual se mantendría la discusión de ambos proyectos en las Cortes, pero con el compromiso de los socialistas de aceptar un nuevo reenvío del PLBRA dictaminado de 7 de octubre a la CRA, para que volviera a dictaminar dicho proyecto, como contrapartida, y procurando acercar posiciones con los radicales.

Sin embargo, en opinión de Malefakis, la presentación del segundo dictamen de 26 de noviembre, confirmaría la creciente oposición política existente entre socialistas y radicales, ya que en vez «de modificar las exigencias socialistas, los miembros de la Comisión pertenecientes a la izquierda republicana las apoyaron con más fuerza que antes», de modo que radicalizaron todavía más su contenido ${ }^{99}$. La opinión de este historiador sobre el alcance del segundo dictamen, es claramente tendenciosa en su no disimulada crítica a los socialistas, cuando de su misma cita se colige, que había una larvada y fuerte oposición, igualmente, entre los radicales y los republicanos de izquierda, en especial con los radical-socialistas. Y en efecto, precisamente el Presidente del Gobierno se referiría a esta seria rivalidad política entre los republicanos de la coalición gubernamental de ese matiz partidario, al manifestar en su diario, en plena negociación para la formación del primer gobierno constitucional, que: «Un Ministerio de concentración republicana tendría la vida dura en las Cortes, pero mejor ambiente en el país. Ahora que conciliar a los radicales-socialistas y a los radicales sería casi imposible» ${ }^{100}$.

\footnotetext{
98 No obstante, hay que tener en cuenta que, en su discurso ante las Cortes de 13 de octubre de 1931, Manuel Azaña había reconocido expresamente que los tres grandes problemas de la República, cuya solución debían "transformar el Estado y la sociedad españoles hasta la raíz», eran: el de las autonomías, el religioso y el «social en su forma más urgente y aguda, que es la reforma de la propiedad» (AZAÑA, M.: Op. cit., p. 345). A pesar de ello, Santos Juliá ha matizado respecto a la tramitación parlamentaria simultánea del PLBRA y del proyecto constitucional, que el criterio inicial de Azaña, después de formar su primer gobierno en octubre de 1931, era que en las Cortes se simultaneara la discusión tanto del PLBRA como del presupuestario, de forma que se llegasen a votar casi al mismo tiempo que la Constitución. Pero este punto de vista, según este historiador, lo «abandonó enseguida para dirigir todo su esfuerzo a la discusión del texto constitucional y posponer lo demás hasta después de que se resolviera la crisis de gobierno que debería seguir a su votación" (JULIÁ, Santos: Manuel Azaña. Una biografía política, Madrid, 1991, $1^{a}$ reimpresión, p. 186).

99 MALEFAKIS, E.: Op. cit., p. 226. El $2^{\circ}$ Dictamen fue debatido y finalmente aprobado en la sesión de la CRA de 25 de noviembre, cuya acta y la del día siguiente son las únicas conservadas que se refieren a este segundo dictamen, en donde sólo hay referencias sobre el resultado y el acuerdo de presentación del mismo al.Pleno, sin que conste ninguna información adicional sobre debates, discrepancias, votaciones, etc.

100 AZAÑA, M.: Op. cit., p. 564, Anotación de 13 de diciembre de 1931. Por su parte, Alejandro Lerroux escribiría en Mis memorias, refiriéndose despectivamente a los ministros del PRRS, Mar-
} 
Además, Malefakis ha atribuido, con notable desacierto en verdad, una mayor radicalización al segundo dictamen, cuando dicho dictamen supuso un claro intento por incorporar algunas de las tesis de los radicales, propuestas por Hidalgo en su voto particular. En este sentido, es especialmente lamentable la errónea imputación que ha hecho a a la mayoría gubernamental de socialistas y republicanos de izquierda de la CRA, de haber introducido como causa de expropiación las tierras pertenecientes a la Iglesia y a las Comunidades religiosas, cuando ya las incluía en su voto particular (art. 9, apdo. c). el mismo vocal radical (al igual que había hecho en el suyo, Díaz del Moral). Igualmente, se incluyeron como nuevos supuestos expropiatorios los bienes rústicos del patrimonio de la Corona y los que fueran de propiedad particular del último rey, y los adjudicados al Estado por razón de deuda o los que poseyera en propiedad privada, que también los había propuesto, como ya se dijo, Diego Hidalgo (apdos. a y b del art. 9), como, así mismo, Díaz del Moral.

El Dictamen, nuevamente redactado, del PLBRA se presentaría a las Cortes el 26 de noviembre por el vicepresidente de la CRA, Lucio Martínez Gil, en cuyo nombre solicitó la retirada del primer Dictamen, que fue aceptada por la Mesa $^{101}$. En la introducción, la Comisión afirmaba que en él no se abordaban los muy diversos problemas del agro español que demandaban normas específicas de regulación (régimen del trabajo campesino, crédito agrícola, concentración parcelaria, repoblación forestal, rabassa morta, foros, rescate de bienes comunales, etc.), sino que la atención preferente se dirigía a «facilitar el acceso a la tierra de aquellas familias campesinas» que soportaban la angustia del paro prolongado, en gran parte debido a la «injusta distribución de la propiedad rústica y a tradicionales deficiencias en la explotación agrícola». Este segundo Dictamen regulaba con mejor sistematización las bases del anterior, ahora reducidas de 24 a 19, presentando pocas novedades respecto al mismo, algunas de las cuales, no suponían, desde luego, un giro en el sentido más radical interpretado por Malefakis. Caso, por ejemplo, de la supresión de la aplicación preferente del programa de asentamientos en los términos municipales de todas las provincias del territorio nacional, cuando existiera en ellos un grave problema de paro campesino, tal y como preveía el primer dictamen, en lo que

celino Domingo y Álvaro de Albornoz, que: «no habían pasado de ser unos rapsodistas que en su breve travesía por la vida política no habían creado nada más que un pobre plagio de la política francesa, el Partido titulado Radical-Socialista, que no fue lo uno ni lo otro, sino colector de disidentes, incubador de ambiciosos y lacayo de todas las demagogias» (LERROUX, Alejandro: Mis memorias, Madrid, 1963, p. 547).

${ }^{101}$ DSCC, núm. 81, 26 de noviembre de 1931, p. 2.676. El Dictamen está publicado en el mismo número en el Apéndice $8^{\circ}$. En la sesión de la CRA de 27 de noviembre consta en acta el acuerdo de presentación del dictamen a la Mesa de las Cortes, con la asistencia de ocho vocales y la firma del secretario, Álvarez Mendizábal, y del vicepresidente, Martínez Gil. Esta acta es la última existente en el archivo del Congreso de los Diputados correspondiente al año 1931.

Hispania, LXIV/1, núm. 216 (2004) 267-324 
había sido una de las modificaciones más «izquierdistas» introducidas en el PLBRA de agosto ${ }^{102}$.

Donde sí se introducían modificaciones de importancia, no obstante, era en la base $6^{a}$, que regulaba la formación del inventario en el que tenían que incluirse todas las tierras expropiables por causa de utilidad social, $\mathrm{y}$ donde se relacionaban éstas, de acuerdo con un orden de prelación muy bien sistematizado, que detallaba hasta 15 tipos de tierras susceptibles de expropiación, incorporando; en parte, como acabamos de señalar, las propuestas por Díaz del Moral y por Diego Hidalgo en sus votos particulares al anterior Dictamen (tierras de la Corona, del último rey y de la Iglesia y Comunidades religiosas) ${ }^{103}$. El resto de tierras sujetas eran similares, pero con el añadido de respetar para sus titulares unas reservas de propiedad terrateniente — que, ciertamente, no sólo no suponían una mayor radicalización a la izquierda, sino que, por el contrario, eran un claro signo de moderación, en la mayor parte de los casos, tanto respecto del PLBRA, como del primer Dictamen, e incluso respecto de la propia LBRA de 1932, que no las reconocían dentro de las mismas causas expropiatorias-, que se hacían equivaler a topes máximos de renta catastral, variables según los supuestos. Así, por ejemplo: las que superaban una extensión equivalente al $20 \%$ o más de la superficie total del término municipal (motivo de presión social, recordemos), con reserva a favor del propietario expropiado de una superficie cuya renta catastral no superase las 3.000 pesetas; las incultas, susceptibles de cultivo permanente en una extensión superior al $50 \%$ de su superficie total (en el primer dictamen, no se especificaba ningún porcentaje mínimo de superficie cultivada); etc.

Entre las restantes tierras expropiables se encontraban, sin ánimo de ser exhaustivo, las adjudicadas al Estado por deudas, herencia o legado, y las que poseyera con el carácter de propiedad privada (causa propuesta tanto por Diego Hidalgo como por Díaz del Moral, que era innovadora respecto al anterior Dictamen, salvo para el caso de las adjudicadas por deudas a la Hacienda Pública); las de buena calidad próximas a los núcleos urbanos, poblados y caseríos y vías de comunicación, cuya cabida excediera de 50 hectáreas de secano y de 5 en regadío (aquí sí se reducía considerablemente el tope máximo de superficie

102 Tanto la ponencia de la CTA como el PLBRA de agosto de 1931, prescribían la aplicación preferente de los asentamientos, única y exclusivamente en los términos municipales de las provincias especificadas en una primera fase, por razón del grave desempleo campesino allí existente. El primer dictamen de la CRA incluyó, además, las tierras de señorío, independientemente de la provincia donde radicasen, junto a la causa del grave paro campesino, como causa adicional aplicable en todo el territorio nacional. El segundo dictamen, en fin, eliminaría este motivo a cambio de matizar que los asentamientos tambíen podrían aplicarse en donde hubiera tierras del Estado, lo cual implicaba un indudable viraje conservador, en términos comparados.

${ }_{103}$ El diputado radical Diego Hidalgo mantuvo, no obstante, el mismo voto particular a la totalidad presentado al primer dictamen para el segundo, por lo que la mesa presidencial lo consideró como reproducido (DSCC, núm. 83, de 1 de diciembre de 1931, p. 2.735). 
respetado para sus dueños en el anterior Dictamen, en lo que parecía más una lúcida rectificación de tipo técnico - de cara a su viabilidad como supuesto expropiatorio-, que una premeditada radicalización, al estar este tipo de tierras de ruedo, ya bastante repartidas o, en todo caso, muy fragmentadas, incluso en las áreas latifundistas), cuando no estuvieran cultivadas directamente por sus dueños, o cuando lo estuviesen, pero de forma deficiente (esta puntualización aclaraba, frente a la mayor ambivalencia del anterior dictamen - como se matizó-, que quedaban sin afectar las eficazmente explotadas, en lo que podía interpretarse como otra concesión a los radicales); etc.

El régimen de excepciones, así mismo, comprendía: los bienes comunales municipales; los estatales y los provinciales que no fueran privados; las tierras de explotación forestal, y las de pasto, no cultivables de forma permanente en el $75 \%$ de su superficie (en el anterior dictamen el criterio de excepción era más restrictivo, es decir, que perjudicaba más a sus propietarios, porque no se condicionaba a ningún porcentaje de viabilidad específico, y como mínimo, en términos relativos sobre el total de dicha superficie) ${ }^{104}$; y las que, a instancia de parte, fuesen de ejemplar explotación y sirviesen «como tipo de perfección técnica y económica» (base $7^{a}$ ). No se exceptuaban expresamente, pero también quedaban sin afectar (en lo que era, indudablemente, otra modificación favorable a las tesis moderadas de los radicales), las tierras explotadas directamente por sus dueños si lo hacían de forma eficaz, de acuerdo con la interpretación a sensu contrario del número 12 de la base $6^{\mathrm{a}}$ (expropiación de las cultivadas directamente de forma deficiente). También implicaba, en fin, un rotundo cambio de signo más que moderado, conservador, el que dejaran de ser expropiables las tierras de origen señorial que hubiesen sido adquiridas por sus actuales propietarios por transmisión contractual en los últimos diez años, que sí lo eran de acuerdo con el anterior Dictamen, siguiendo lo propuesto en el proyecto de Alcalá-Zamora.

En cuanto a las indemnizaciones, el nuevo dictamen establecía, como el precedente, que sólo se indemnizarían las mejoras realizadas en el fundo por sus dueños, en los supuestos de expropiación de tierras de origen señorial, y en las de la Iglesia y Comunidades religiosas. Para la indemnización en los restantes supuestos, el criterio de capitalización se valoraba de acuerdo con la renta catastral o amillarada, mediante la aplicación de unos tipos mucho más altos

\footnotetext{
${ }_{104}$ Sobre la exigencia de este porcentaje mínimo de cultivo permanente para que este tipo de tierras fuesen afectadas, Pascual Carrión, confirmando nuestra argumentación sobre la índole moderada de este requisito específico, llamaría críticamente la atención al analizar el PLBRA dictaminado de Marcelino Domingo, de abril de 1932 (que literalmente seguía, en este sentido, lo prescrito por este segundo Dictamen de noviembre de 1931), porque, en su opinión, quedaban exceptuadas así «un gran número de dehesas que tienen más de un 25 por ciento de malos terrenos, cosa muy corriente en las grandes fincas" (CARRIÓN, P.: La reforma agraria... Op. cit., p. 125). No obstante, cuando las dehesas no laborables tuvieran origen señorial, sí podían ser expropiables en toda aquella superficie que superara el equivalente a 3.000 pesetas de renta catastral (reserva exceptuada), con el fin de constituir el patrimonio comunal del término donde se hallaren.
} 
que los del anterior dictamen (con la consiguiente reducción de las indemnizaciones a percibir), salvo para los tramos de renta inferiores, claramente menos perjudiciales, en especial para los pequeños y medianos propietarios afectados: hasta 30.000 pesetas de renta catastral o amillarada, el Dictamen mantenía o reducía (hasta dos puntos porcentuales) los tipos aplicables en el primero; a partir de dicho umbral, los tipos se elevaban notablemente, en evidente perjuicio (con las matizaciones que se hacen más adelante) de los terratenientes afectados de mayor riqueza:

\section{CUADRO 3}

TIPOS COMPARADOS DE CAPITALIZACIÓN DE LA RENTA DE LAS TIERRAS EXPROPIABLES, SEGÚN LOS DICTÁMENES DEL PLBRA DE LA CRA, DE 7 DE OCTUBRE Y DE 26 DE NOVIEMBRE DE 1931

\begin{tabular}{lcccc}
\hline UMBRALES DE RENTA EN PESETAS & TIPO DICT. I & \multicolumn{2}{c}{ TIPO DICT. II } \\
\hline inferior a 10.000 & & $4 \%$ & $(-2 \%)$ \\
de 10.000 hasta 20.000 & & $5 \%$ & $(-1 \%)$ \\
inferior a 20.000 & $6 \%$ & & \\
de 20.001 hasta 30.000 & $7 \%$ & $7 \%$ & \\
" 30.001 " 50.000 & $8 \%$ & $10 \%$ & $(+2 \%)$ \\
" 50.001 " 100.000 & $9 \%$ & $15 \%$ & $(+6 \%)$ \\
"100.001 " 200.000 & $10 \%$ & $25 \%$ & $(+15 \%)$ \\
"200.001 en adelante & $12 \%$ & $50 \%$ & $(+38 \%)$ \\
\hline
\end{tabular}

FUENTE: Elaboración propia, según las Bases $14^{\mathrm{a}}$ y $8^{\mathrm{a}}$, respectivamente, de los Dictámenes del PLBRA citados

En este sentido, Malefakis ha considerado este dictamen mucho más radical que el anterior, porque los tipos de capitalización eran muy discriminatorios y perjudiciales para los niveles superiores de renta catastral, ya que: «Sólo los propietarios de extensiones muy pequeñas de tierra recibirían una cantidad algo parecida al valor en el mercado de sus fincas» ${ }^{105}$. Pero al ser, probablemente, este grupo de pequeños y medianos propietarios uno de los más afectados por la normativa expropiatoria (en particular, por la causa de arrendamiento sitemático y por las relativas a las tierras no explotadas directamente), lo que ocurriría, en realidad, es que, en estos sectores, las indemnizaciones serían mucho más gravosas para el Estado, frente a la capitalización contemplada en el primer dictamen, por acercarse dichos tipos al valor de mercado equiparable de las tierras. Con lo que podemos interpretar que los cambios experimentados en

105 Malefakis, E.: Op. cit., pp. 226-227. 
materia de capitalización de la renta, supusieron, de nuevo, otro viraje más moderado, en favor de los sectores de la propiedad mencionados, y en detrimento de las arcas del Tesoro, que verían cómo las indemnizaciones se encarecían en dichos tramos de renta, sobre todo, cuando las valoraciones de los tipos de capitalización se harían por fincas de forma unitaria, sin que se computaran, a estos efectos, todas las pertenecientes a un mismo propietario de forma acumulada.

En apoyo de esta interpretación, conviene recordar (puesto que ya se hizo referencia antes al estudiar el PLBRA de agosto) cómo Pascual Carrión, al valorar los tipos de capitalización para los umbrales más reducidos de renta catastral, ya había llamado la atención sobre el enorme coste económico de una capitalización con un tipo del $3 \%$, porque equivalía, en su opinión, a treinta y tres veces el líquido imponible, y «se comprende que esta última tasación es en general elevada y no adecuada para una reforma agraria». El mismo Malefakis viene a respaldar, implícitamente, la tesis de Carrión (y la nuestra), al reconocer que, a diferencia de los propietarios nobiliarios afectados, los sectores de tipo pequeño y mediano, iban a recibir indemnizaciones cercanas a los precios de mercado, constatando así la presumiblemente elevada factura de las indemnizaciones para el Estado.

$\mathrm{Y}$ es que, en realidad, no se trataba tanto de que hubiera unos tipos demasiado altos, incluso confiscatorios, aplicables para los propietarios terratenientes de mayor riqueza, sino del posible volumen de las indemnizaciones abonables atendiendo a los grupos mayoritarios afectados y a la forma de capitalizar por fincas unitarias. Y en este sentido, este mismo historiador, al analizar los tipos de capitalización de la LBRA de septiembre de 1932 (mucho más reducidos en los tramos superiores de renta: en una escala progresiva del 5 al $20 \%$, como tipo máximo), viene a rectificar por completo su criterio anterior, reconociendo implícitamente el error de partida, al sostener que, a primera vista, uno de los aspectos más radicales de la reforma era el relativo a las medidas compensatorias, incluso más que el de las categorías de tierra expropiable, pero que, en realidad, sus efectos «fueron menos dañinos de lo que parecían», porque sólo se aplicaron tipos «verdaderamente confiscatorios» a los tramos de renta imponible superiores a 60.000 pesetas, y porque, y aquí está la clave de la cuestión, «aunque la propiedad global de muchos propietarios excedía estos límites, eran muy pocas las fincas individuales de esta clase [la cursiva es del autor]». En consecuencia, las indemnizaciones se encarecerían en su mayor parte por la aplicación de unos tipos de capitalización de la renta catastral o amillarada más cercanos al valor de mercado de la tierra de lo previsto, tanto desde el punto de vista de los propietarios afectados pequeños y medianos, como de los tipos realmente aplicables al valorarse las fincas de los mayores propietarios de forma unitaria a efectos indemnizatorios ${ }^{106}$.

106 Las valoraciones de estos dos autores, tanto del PLBRA de agosto de 1931, en el caso del ingeniero agrónomo, como de la LBRA de septiembre de 1932, en el caso del historiador, en CARRIón, P.: La reforma agraria... Op. cit., p. 119, y en MALEFAKIS, E.: Op. cit., p. 262, respectivamente. 
El importe de dichas indemnizaciones era abonado en inscripciones de Deuda Pública interior al 4\%, pudiendo el tenedor disponer únicamente del $10 \%$ de las mismas por cada año, y «siendo el resto intransferible por actos inter vivos e imbargable [sic] durante un plazo mínimo de cinco años» que el Gobierno podía aumentar hasta diez (base $8^{a}$ ). Esta disponibilidad restringida de la capacidad para transmitir los títulos de deuda también cabe interpretarse como una modificación, en sentido más moderado, del primer dictamen, ya que en éste sólo se reconocían como únicas transmisiones de dichos títulos, las efectuadas mediante herencia o legado.

En conclusión, entendemos que el segundo Dictamen de 26 de noviembre de 1931 no sólo no implicó un supuesto giro más radical hacia la izquierda, comparando con el anterior Dictamen de 7 de octubre, tal y como ha sostenido Malefakis (justificando así la salida del PRR de la coalición de gobierno republicano-socialista), sino que, por el contrario, los cambios experimentados por el PLBRA permiten defender la tesis opuesta de que, en realidad, con dicho Dictamen, la mayoría gubernamental en la CRA trató, en efecto, de limar seriamente asperezas y acercar posiciones con los radicales en materia de reforma agraria, de cara a reforzar la estabilidad del nuevo Gabinete presidido por Manuel Azaña. Esta es, en nuestra opinión, la interpretación más coherente que se deduce del análisis de las enmiendas introducidas y del indudable viraje moderado que implicaban, recordemos, en apretada síntesis: supresión de la causa de la existencia de grave paro campesino para implantar los asentamientos en el conjunto del territorio de la República; inclusión dentro del orden de prelación de tierras expropiables, por iniciativa del radical Diego Hidalgo, de las pertenecientes a la Corona, al patrimonio del último rey, a la Iglesia y Comunidades religiosas, etc.; reconocimiento de reservas en tierras o en renta catastral en los supuestos expropiatorios en beneficio de los propietarios afectados; exigencia de un porcentaje mínimo de cultivo permanente potencial para admitir la expropiación de las tierras incultas; exención inequívoca del eficaz cultivador directo, sin necesidad de que la explotación fuera ejemplar y/o modélica; tipos de capitalización más gravosos para la Hacienda Pública en los tramos de renta catastral o amillarada más bajos, en beneficio de los pequeños y medianos propietarios; menor restricción a la posible transmisión de los títulos de Deuda Pública, etc.

En consecuencia, de la investigación efectuada parece deducirse, frente a la tesis historiográfica tradicional desde Malefakis, que el segundo Dictamen de la CRA no fue, en sí mismo, una de las causas fundamentales para que los radicales robustecieran su creciente oposición a los socialistas, en particular, de cara al abandono de la coalición gubernamental, una vez aprobada la Constitución el 9 de diciembre de 1931, sino que, por el contrario, fue más bien uno de los pretextos políticos más hábilmente utilizados por los dirigentes del PRR para, en asumida representación de los sectores medios de la propiedad terrateniente presumiblemente más perjudicados por la reforma agraria, pasar a ejercer, de inmediato, la oposición, y plantear, después, una alternativa de gobierno repu- 
blicano, sin socialistas, con la presidencia en manos de Lerroux ${ }^{107}$. Sobre todo, teniendo en cuenta la condición, cada vez más conscientemente asumida por los radicales, de ser la fuerza política más cualificada dentro de las Constituyentes para defender los intereses sociales y económicos de los sectores crecientemente soliviantados contra el Gobierno y su concreto proyecto de reforma agraria ${ }^{108}$.

El segundo Dictamen provocaría, en fin, un rechazo rotundo por parte de Lerroux y su partido, cada vez más enfrentado a los socialistas. Y en efecto, una vez aprobada la Constitución, el 9 de diciembre de 1931, en las negociaciones para formar su segundo Gobierno, primero Constitucional de la República, Azaña dejaría constancia de las dificultades políticas para hacerlo incluyendo a los radicales, y para la tramitación del proyecto de ley de reforma agraria, cuando escribió en su diario: «Enumero mi programa parlamentario, que contiene las principales leyes orgánicas que pide la Constitución. Le parece [a Fernando de los Ríos] muy bien. (Lo mismo le han parecido a Lerroux, que 'no disputará por una ley de más o de menos'; pero advirtiendo que no está conforme con el dictamen sobre la reforma agraria)». Al Presidente de la República, Alcalá-Zamora, tampoco le pareció adecuado, ya que tras reunirse con él en Palacio, y recibir el encargo de formar gobierno el 15 de diciembre, Azaña, así mismo, anotó: «está conforme con mi plan parlamentario, pero expresa el deseo de que se suavice el proyecto de reforma agraria para no indisponer con la República a la clase media terrateniente»109.

El Gobierno, por tanto, no presionaría para que se incluyera el proyecto dictaminado en el orden del día de las Cortes, aun cuando Azaña había encarecido la pronta aprobación parlamentaria del Estatuto de Cataluña, el Presupuesto, la ley Electoral y, también, la ley Agraria, en el discurso de presentación de su programa de gobierno ante las Cortes Constituyentes, el 17 de diciembre, ya con los radicales fuera del gabinete ${ }^{110}$. Pero es que el rechazo radical y de los sectores patronales agrarios al segundo Dictamen del PLBRA, a pesar de estar amparado por la mayoría gubernamental tanto dentro de la CRA como en el propio Gobierno consitucional, hacía ver a las minorías republicanas de izquierda representadas en el mismo (PRRS, FRG y AR, en espe-

\footnotetext{
107 Para el otro ministro radical en el gobierno cesante, Diego Martínez Barrio, la negativa a entrar en el gobierno constitucional se produjo porque el líder del PRR, «se consideraba burlado (...). La actitud de Azaña, rechazando el papel de presidente interino de un gobierno puente entre el provisional con socialistas y el radical sin ellos, plan concreto de Lerroux, primero le asombró y luego le indignó» (MARTínEZ BARRIO, Diego: Memorias, Barcelona, 1983, p. 99).

108 «Fuerza engendrada en la sociedad y en la política por la oligarquía de la Restauración, el partido radical retornaba al servicio de la oligarquía en la República. Ambos tenían de común el modo de concebir la política, la laxitud moral y la idea del poder como fin en sí mismo» (RAMOS OliveirA, Antonio: Historia de España, Tomo III, México, 1952, p. 176).

${ }^{109}$ Ambas citas, en AZAÑA, M.: Op. cit., pp. 566 y 574; Anotaciones de 13 y 15 de diciembre de 1931 , respectivamente.

110 La referencia a la necesidad de aprobar con prontitud las leyes citadas, en el discurso ante las Cortes de 17 de diciembre de 1931, en AZAÑA, M.: Op. cit.; pp. 590-591.
} 
cial), la necesidad de abordar un nuevo proyecto de reforma agraria bajo parámetros de mayor moderación aún, que no indispusieran tan rotundamente a las clases medias contra el Gobierno ${ }^{111}$.

\footnotetext{
111 En este sentido, pocos días después de la presentación del Gobierno Constitucional republicano-socialista, Alejandro Lerroux, en un discurso en la Monumental de Madrid, el 21 de febrero de 1932, recogería todo el sentir y todas las preocupaciones de las clases medias propietarias terratenientes sobre el alcance de la reforma agraria, cuando, tras aludir a la enorme complejidad y dificultad de la misma (variedad del agro, situación económica del país, estado de confianza, pago de indemnizaciones justas y legítimas, etc.), afirmó explícitamente que: «todo esto implica una obra que ahora sí que pudiera llamarse obra de romanos, que no se puede realizar por la ponencia de un Gobierno ni por la ponencia de unas Cortes Constituyentes». Por todo ello, continuó, el PRR «se ha de interponer entre la ilusión excesiva y la realidad para que lo que se acuerde no sea después letra muerta en la Gaceta o en el Diario de Sesiones, sino preceptos de posible realización, a los cuales se allanen las clases interesadas porque en ellos vean reflejada perfectamente la justicia, y no solamente la justicia, sino una manera de cooperación a la misma, como en los contratos de seguro los asegurados pagan una parte de su propiedad para asegurarse contra cualquier siniestro el resto de la misma” (LIBRO DE ORO DEL PARTIDO REPUBLICANO RADICAL 1864-1934, Madrid, s.f. [¿1935?], p. 217). El símil actuarial del líder del PRR era ciertamente muy ilustrativo de las preocupaciones de los sectores terratenientes de la pequeña y, sobre todo, mediana propiedad más perjudicados por la reforma según la previsión de los dictámenes de 1931. Por todo ello, no podemos sorprendernos de que, a pesar del previsible desplazamiento hacia la izquierda de la nueva coalición gubernamental republicano-socialista, y de que cupiera esperar una rápida y más audaz reforma agraria tras el paso a la oposición de los radicales, ocurriera, en matización de Santos Juliá, «sin embargo, lo contrario» (JULÁ, Santos: Manuel Azaña... Op. cit., p. 186). Y es que, en definitiva, el nuevo gobierno presidido por Azaña no quiso «imponer el dictamen", precisamente porque con el mismo «había asustado a toda la burguesía agraria» (TUÑón DE LARA, M.: Op. cit., p. 861).
}

Hispania, LXIV/1, núm. 216 (2004) 267-324 